TEORIA SOCIAL E CRÍTICA DO DIREITO PENAL:

O PROBLEMA DO RECONHECIMENTO DA VÍTIMA

Tese de Doutorado

Orientador: Professor Associado Eduardo Saad-Diniz

UNIVERSIDADE DE SÃO PAULO

FACULDADE DE DIREITO

São Paulo - SP

2019 


\section{TEORIA SOCIAL E CRÍTICA DO DIREITO PENAL: O PROBLEMA DO RECONHECIMENTO DA VÍTIMA}

Tese de Doutorado apresentada a Banca Examinadora do Programa de PósGraduação em Direito da Faculdade de Direito da Universidade de São Paulo, na área de concentração Direito Penal, sob a orientação do Professor Associado Dr. Eduardo Saad-Diniz.

UNIVERSIDADE DE SÃO PAULO

FACULDADE DE DIREITO

São Paulo - SP 
MARIN, Gustavo de Carvalho.

Teoria social e crítica do direito penal: o problema do reconhecimento da vítima. São Paulo-SP, 2019.

223 p.; $30 \mathrm{~cm}$

Tese de Doutorado apresentada à Faculdade de Direito da Universidade de São Paulo

Orientador: Prof. Associado Dr. Eduardo Saad-Diniz.

1. Direito Penal. 2. Teoria Social. 3. Vitimologia. 4. Vítima. 5. Reconhecimento 


\section{RESUMO}

MARIN, Gustavo de Carvalho. Teoria social e crítica do direito penal: o problema do reconhecimento da vítima. Tese de Doutorado. Faculdade de Direito, Universidade de São Paulo, São Paulo, 2019.

Os avanços da pesquisa vitimológica têm recebido escassa atenção dos estudos mais estritamente jurídico-penais. Em verdade, o reposicionamento da vítima como categoria de análise científica encontra escasso abrigo na teoria do direito penal, na qual prevalece ainda a ideia de que a perspectiva das pessoas que concretamente sofreram com o crime pouco ou nada têm a contribuir com os debates sobre imputação, ou mesmo acerca das justificações morais em torno das intervenções punitivas. Adotando um diálogo ainda pouco explorado entre ciência jurídico-penal e as teorias sociais de orientação crítica, a pesquisa se dedica a analisar essas justificações que fundamentam a posição comumente atribuída à vítima no direito penal. Destarte, busca identificar as debilidades dessas teses tradicionais e analisar as possibilidades de uma reorientação conceitual das ideias penais a partir da introdução da noção de reconhecimento da vítima. A pesquisa doutoral trabalhará com as hipóteses de que: (i) o recurso ao diálogo interdisciplinar com a teoria social pode contribuir com a análise de problemas mais marcadamente jurídico-penais, proporcionando ao direito penal novas possibilidades de autorreflexão e autocorreção no que concerne a suas teses e respostas; e (ii) a categoria do reconhecimento, tal como definida pela filosofia social, possui elevada capacidade de rendimento para uma reorientação das ideias penais, reintroduzindo a vítima como sujeito relevante para os debates centrais em direito penal.

Palavras-chave: Direito Penal; Teoria Social; Vitimologia; Vítima; Reconhecimento. 


\begin{abstract}
MARIN, Gustavo de Carvalho. Social theory and the critique of criminal law: the problem of the recognition of the victim. Doctoral Thesis. University of São Paulo, Law School. São Paulo, 2019.
\end{abstract}

The advances of victimological research have received an insufficient attention from studies in criminal law. Actually, the repositioning of the victim as a category of scientific analysis is hardly accommodated within criminal law theory, in which is still prevalent the idea that the perspectives of those who have suffered with crime have little or nothing to contribute regarding the debates about imputation, or even concerning the moral justifications of the punitive interventions. By adopting a still little explored dialogue between criminal-legal science and the critical social theories, the research examines the justifications underlying the position commonly attributed to the victim within criminal law. Thus, it seeks specifically to identify the weaknesses of these traditional theses, also analyzing the possibilities of a conceptual reorientation of criminal law ideas by introducing the notion of recognition of the victim. Therefore, this doctoral research works with the hypothesis that: (i) recurring to an interdisciplinary dialogue with social theory might contribute to the analysis of legal-criminal problems, providing criminal law with new possibilities of self-reflection and self-correction concerning its theses and responses; and (ii) the category of recognition as defined by social philosophy has a high capacity for a reorientation of criminal law ideas, reintroducing the victim as a relevant subject for the central debates of criminal law.

Keywords: Criminal Law; Social Theory; Victimology; Victim; Recognition. 
"Fui à zona de Tchernóbil. Já estive lá muitas vezes. E lá eu entendi que era impotente. Que não compreendo. E esse sentimento de impotência está me destruindo. Porque não reconheço este mundo. Tudo nele mudou. Até o mal é outro. O passado já não me protege. Não me tranquiliza. Não dá respostas. Antes sempre dava, agora não mais. O futuro me arruína, não o passado. (Pensativo.) Para que as pessoas recordam? É a minha pergunta. Mas eu falei com você, pronunciei algumas palavras. E compreendi alguma coisa... Agora não me sinto tão sozinho. Mas o que acontece com os outros?"

(Piotr S., em depoimento a Svetlana Alexijevich Vozes de Tchernóbil, Cia. das Letras, 2016 - trad. Sonia Branco) 
A Oscar (in memoriam) e Onofra. 


\section{SUMÁRIO}

1. INTERAÇÃO FUNCIONAL ENTRE TEORIA SOCIAL E DIREITO PENAL

1.1. Fundamentos de teoria social

1.2. Interação entre teoria social e ciência do direito penal: principais críticas

1.3. Bases para um novo diálogo entre o jurídico-penal e o teórico-social

2. AS TEORIAS DO RECONHECIMENTO: FILOSOFIA, TEORIA SOCIAL E A CRÍTICA DO DIREITO

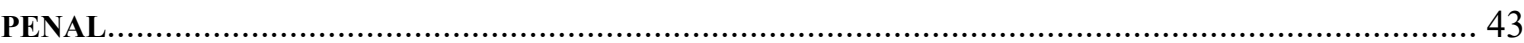

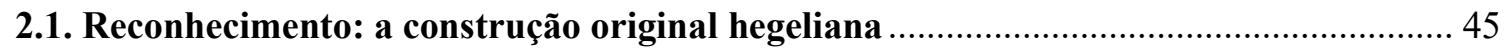

2.1.1. Das influências de Fichte à crítica a Hobbes.............................................................. 45

2.1.2. O reconhecimento no período de Jena ......................................................................50

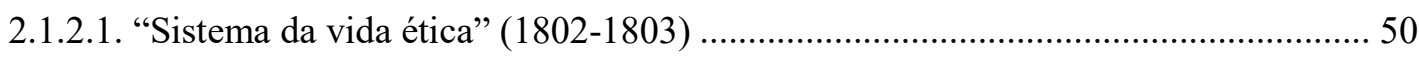

2.1.2.2. "Sistema da filosofia especulativa" (1803/1804) ...................................................... 54

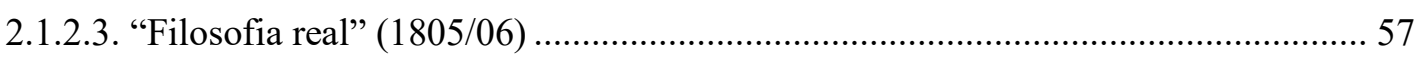

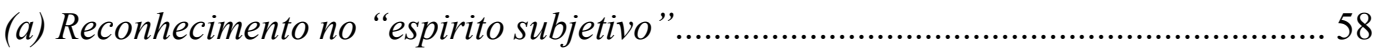

(b) $O$ "espirito real" e o reconhecimento nas relações jurídicas...................................... 62

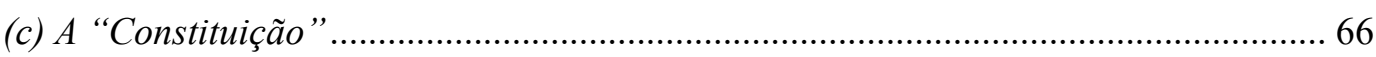

2.1.3. O reconhecimento nas obras posteriores de Hegel ..................................................68 68

2.1.3.1. "Fenomenologia do espírito" (1807) e "Enciclopédia das ciências filosóficas" (1817)

2.1.3.2. "Princípios da Filosofia do Direito" (1820): o reconhecimento no epicentro da filosofia política

2.2. A recepção do reconhecimento pela filosofia social 88

2.2.1. A filosofia social como teoria social crítica. 88

2.2.2. "Reconstrução racional" $e$ consenso........................................................................ 94

2.2.3. A consolidação de um "paradigma do reconhecimento" ............................................... 103

2.2.3.1. Teoria do reconhecimento como "gramática moral dos conflitos sociais" ........... 108

2.2.3.2. Reconhecimento como meio de formação da "eticidade democrática" ................ 114

2.3. Teorias do reconhecimento e avaliação institucional: uma orientação normativa à crítica da posição da vítima no direito penal 
3.2. Retorno à vítima e os desenvolvimentos da vitimologia 132

3.3. Recrudescimento punitivo como efeito colateral do redescobrimento da vítima: análise crítica e propostas para uma releitura do problema 143

3.3.1. A instrumentalização da vítima nos discursos securitários.......................................... 143

3.3.2. Movimentos de vítimas como fatores de desestabilização do direito penal? .............. 147

3.3.3. Direitos da vítima e do ofensor: jogo de soma-zero ou tensão conciliável?............... 154

4. O RECONHECIMENTO DA VÍTIMA COMO REORIENTAÇÃO DAS IDEIAS PENAIS?

4.1. O lugar da "vítima redescoberta" nas ideias penais

4.1.1. Processo penal: redimensionamento da vítima e o reconhecimento de direitos.

4.1.2. Direito penal: algumas portas abertas, muitas outras fechadas.

4.1.2.1. Recepção da pesquisa vitimológica interacionista pelas teses dogmático-penais. 169

4.1.2.2. Linhas críticas da pesquisa vitimológica e o ceticismo penalista.

4.2. Reconhecimento da vítima como desafio de legitimação do direito penal

4.3. Reconhecimento da vítima e as bases para uma revisão das teorias da imputação

CONCluSão

REFERÊNCIAS BIBLIOGRÁFICAS 


\section{INTRODUÇ̃̃o}

Originalmente dedicada à compreensão das interações entre ofensor e vítima na causação dos eventos que levaram à vitimização, a vitimologia experienciou significativos desenvolvimentos desde estes momentos iniciais. Especialmente no último quarto do século $\mathrm{XX}$, os estudos vitimológicos incorporaram uma agenda positiva de pesquisa, orientada por uma compreensão da vítima como sujeito empírico cujas experiências individuais de sofrimento e necessidades delas decorrentes passaram a importar como genuíno objeto de análise. A história da vitimologia como disciplina envolve não apenas uma diversificação metodológica, mas especialmente essa ampliação de seu objeto: para além da dinâmica interacionista, a vitimologia passa a se atentar às estruturas sociais que condicionam os processos de vitimização, a atuação crítica da vítima com relação a essas estruturas, a identificação dos interesses e necessidades das pessoas afetadas pelo delito, além do efetivo desempenho das instituições e policies em atendê-los.

Não obstante os relevantes resultados obtidos pelos significativos avanços da pesquisa vitimológica, têm eles recebido escassa atenção dos estudos mais estritamente jurídico-penais. Em verdade, o redimensionamento da vítima como categoria de análise científica encontra parco abrigo na teoria do direito penal, na qual parece prevalecer ainda a ideia de que a perspectiva das pessoas que concretamente sofreram com o crime pouco ou nada têm a contribuir com os debates sobre imputação ou acerca das justificações morais em torno das intervenções punitivas. Adotando um diálogo ainda pouco explorado entre ciência jurídico-penal e as teorias sociais de orientação crítica, esta pesquisa se dedica a analisar as justificações que fundamentam a posição comumente atribuída à vítima pelo direito penal; buscando, especificamente, identificar as debilidades dessas teses tradicionais e analisar as possibilidades de reorientação das ideias penais - mais conceitual do que dogmática - a partir da ideia de reconhecimento da vítima.

Isso implica o estabelecimento de duas hipóteses fundamentais de pesquisa. A primeira é de que a teoria social possui capacidade de rendimento para proporcionar à ciência do direito penal novas orientações de autorreflexão e autocorreção, sugerindo novas estratégias de pesquisa e marcos teóricos para a análise de problemas marcadamente 
jurídico-penais. Esta hipótese possui como fundamento os postulados da ciência jurídica de que um direito comprometido com ideias de responsividade e adaptabilidade social tende a ser receptivo a uma interdisciplinaridade criteriosamente operacionalizada, podendo as teorias sociais servirem como relevante fonte de informações sobre em que medida as respostas conferidas pela ordem jurídico-penal efetivamente se coadunam com a realidade dos conflitos sociais juridicamente regulados.

A segunda hipótese de pesquisa reside na compreensão de que a categoria filosófica do reconhecimento, e suas respectivas atualizações pela teoria social, possuem potencial analítico e crítico para fundamentar uma reorientação das ideias penais com relação à vítima, superando as teses mainstream de indiferença com relação a ela. A ideia é, em se confirmando a hipótese de pesquisa referente às vantagens do diálogo interdisciplinar com a teoria social, especificar a discussão com relação ao conflito vitimal. O alinhamento da tese a um "paradigma do reconhecimento", característico do campo filosófico-social, dá-se em virtude da capacidade desta vertente de aliar, de um lado, análises das concretas dinâmicas sociais (como são); e, de outro, uma orientação normativa no sentido de apontar caminhos que poderiam fundar um aprimoramento ético dessas práticas e instituições, com base em critérios teórico-sociais previamente definidos (como devem ser).

A delimitação do objeto de pesquisa tem como ponto de partida a percepção de que é necessário o desenvolvimento de empreendimentos teóricos que recondicionem a vítima como sujeito relevante do conflito sobre o qual o direito penal se pretende incidir; sem, contudo, que isso implique vulneração dos direitos do ofensor e eventuais distorções que poderiam advir de uma inadequada abertura da ordem jurídico-penal a elementos emocionais que frequentemente ocupam a posição da vítima (Opferstatus). No contexto especificamente brasileiro, o que predominam são estudos dogmáticos cuja recepção aos estudos vitimológicos se restringem aos estágios iniciais da vitimologia, orientados à compreensão de como a vítima poderia contribuir para seu próprio sofrimento. Não obstante os relevantes resultados obtidos em termos de uma mais precisa circunscrição dogmática do conceito de injusto, a verdade é que as ciências criminais têm se desenvolvido predominantemente ao arrepio da evolução pela qual passou as discussões sobre as vítimas em outras dimensões de pesquisa; negligenciando, assim, a possibilidade desses novos insights sobre a posição da vítima poder contribuir com novos caminhos para interpretação dos problemas penais e com práticas mais sofisticadas de orientação à vítima no Sistema de Justiça criminal. 
Essas abordagens tradicionalmente empregadas pela ciência jurídico-penal para analisar o conflito vitimal parecem ser pouco adequadas às novas demandas por legitimação do poder, apresentadas no contexto das sociedades democráticas modernas. Mais do que um problema de interpretação penal, a revisão das justificações morais em torno da relação vítima/ofensor e seu consequente gerenciamento pelo Sistema de Justiça criminal diz respeito, fundamentalmente, aos próprios desafios de legitimação aos quais o direito penal é submetido. É neste ponto que direito penal, já confrontado com a crítica vitimológica, pode convergir com os influxos teórico-normativos advindos de uma filosofia social do reconhecimento. Uma das mais promissoras linhas de pesquisa em teoria social é justamente no sentido de discutir como as dinâmicas de reconhecimento mútuo transcendem o plano da mera interação individual entre sujeitos (na constituição recíproca de suas identidades), ascendendo ao patamar da institucionalidade: instituições e práticas sociais sujeitas a critérios modernos de legitimação democrática podem ser avaliadas a partir de seu potencial e efetivo desempenho quanto ao reconhecimento dos sujeitos e à realização de suas liberdades. Daí a opção da pesquisa em testar a categoria filosófico-social do reconhecimento como chave de possíveis novas interpretações sobre a regulação jurídicopenal do conflito vitimal.

Tendo em vista a hipótese e delimitação do objeto de pesquisa, o trabalho se norteará por um raciocínio dedutivo, estruturando-se em quatro capítulos:

(i) No Capítulo 1, serão estabelecidos alguns fundamentos de teoria social e explorada sua difícil relação com a ciência do direito penal. Apontando como e por que as teorias penais poderiam ver seu potencial analítico incrementado a partir de um diálogo mais amplo e estruturado com as teorias da sociedade, esta primeira seção da tese se dedica ainda a fixar os parâmetros metodológicos que podem orientar esse diálogo interdisciplinar.

(ii) O Capítulo 2, por sua vez, enfocará o recorte teórico-social escolhido para o estudo do objeto de pesquisa, procurando delimitar conceitualmente a ideia de reconhecimento, a partir de uma análise de suas origens em Hegel; e, em um segundo momento, das respectivas atualizações que o conceito recebeu pela filosofia social contemporânea, no contexto dos esforços empreendidos por esta última em definir um "paradigma do reconhecimento" como nova estratégia de pesquisa. A ideia é demonstrar como o reconhecimento pode ser utilizado como chave de uma crítica filosófica ao direito penal, especialmente quanto às suas relações com a vítima do delito. 
(iii) O Capítulo 3 buscará identificar as bases históricas e justificações filosóficas que sustentam uma determinada posição que a vítima tradicionalmente ocupa na ordem das ideias penais. Mais especificamente, serão apresentados os movimentos históricos e teóricos de "neutralização" e "redescobrimento da vítima", sedimentando o caminho para que o capítulo seguinte possa discutir como tais teses são recepcionadas em maior ou menor medida no âmbito do direito penal e processo penal.

(iv) O Capítulo 4, a seu turno, realizará uma confluência entre as ideias discutidas até então pela tese, confrontando o tratamento conferido pela vítima na ordem jurídico-penal com os desafios de legitimação das instituições e práticas sociais apresentados pelas teorias do reconhecimento. O ponto é demonstrar como a justificações de neutralização da vítima, ao mesmo tempo em que se permitiram transformar parcialmente a partir dos influxos da pesquisa vitimológica, persistiram como relevante fundamento do tratamento conferido à vítima pela ciência do direito penal e pelo Sistema de Justiça criminal. A ideia é que, mais do que um apontamento de uma eventual situação de denegação de reconhecimento da vítima, seja possível apontar os reflexos conceituais que o seu reconhecimento poderia lançar sobre as ideias penais.

(v) Por fim, na Conclusão, serão consolidados e sintetizados os resultados da revisão do lugar da vítima nas ciências criminais a partir do diálogo interdisciplinar com as teorias críticas da sociedade orientadas pelo paradigma do reconhecimento. 


\section{CONCLUSÃo}

1. A teoria social dedica-se a prover um quadro analítico e filosófico a partir do qual as ciências sociais se desenvolvem em determinados sentidos, fornecendo os ferramentais teóricos que viabilizam ao investigador examinar sistematicamente os dados da realidade social e, na sequência, argumentar junto aos interlocutores de seu estudo acerca dos sucessos e falhas em seus métodos, premissas, estratégias de pesquisa e conclusões. Neste sentido, a teoria social levanta problemas intelectuais a respeito de determinadas esferas da sociabilidade humana, ao mesmo tempo em que delimita um substrato teórico por meio do qual tais problemas possam ser analisados com maior acuidade científica. A tese buscou se alinhar a concepções que buscam equilibrar objetividade descritiva com influxos de teoria normativa; quer dizer, que pautam-se pelo equacionamento entre expor analiticamente a realidade dos aspectos sociais, porém apontando suas debilidades e potencialidades conforme determinados critérios avaliativos.

2. Apesar de o direito penal não poder renunciar a um exame da realidade social com a qual se relaciona, e sobre a qual afinal incide, suas conexões com os estudos em teoria social são controversas. O primeiro ponto de fricção entre as áreas diz respeito a certa desconfiança por parte dos juristas de que a internalização de contribuições teórico-sociais possam dar ensejo a uma mitigação dos critérios de legalidade; é dizer, privilegiando-se fatores extrajurídicos na formulação das decisões de conformação do direito. Esta primeira crítica atenta-se para o direito como ordem normativa voltada à estabilização de expectativas sociais. Já um segundo plano de inquietações refere-se às consequências que a interdisciplinaridade entre teoria social e direito penal poderiam ter para este último não exatamente em sua dimensão ordenativa, mas como ciência - mais especificamente, preocupações com sua autonomia científica e clareza metodológica. A pesquisa buscou demonstrar como os conhecimentos teórico-sociais foram negligenciados nas distintas fundamentações filosóficas do direito penal em sua história, sendo admitidos de modo apenas descontínuo conforme preferências temáticas; e, sobretudo, sem consideráveis preocupações com a definição de parâmetros relativamente universalizáveis de interdisciplinaridade.

3. Para que o recurso interdisciplinar pudesse conjugar a preservação da autonomia científica do direito penal com um melhor aproveitamento dos influxos normativos da teoria social, foram estabelecidos parâmetros metodológicos que orientaram a pesquisa: (i) 
transversalidade (não há uma teoria social com supremacia sobre as demais, de modo que a opção do trabalho por um recorte teórico-social específico se dá em decorrência de considerá-lo com especial capacidade de rendimento para abordar um determinado aspecto de um problema restrito - no caso, os conflitos vitimais em direito penal e as justificações morais que o rodeiam); (ii) responsividade (não obstante o direito diferencie a si mesmo do não-jurídico, ele se permite ser constantemente desafiado por informações e questionamentos advindos da teoria social, encarando tais elementos como oportunidade de autorreflexão e autocorreção); (iii) autonormatividade (apesar de recorrer à interdisciplinaridade, a pesquisa não extrai das contribuições teórico-sociais normas prontamente aplicáveis à dimensão jurídico-penal, tanto por questões de autonomia científica, como não ser possível atribuir normatividade ao não-jurídico - o que as teorias sociais fornecem não são normas, mas orientações normativas que podem informar reorientações por parte do direito penal); (iv) seletividade de perspectivas (necessidade de uma seleção justificada de um recorte teórico-social específico); (v) unilateralidade operacional (as orientações normativas fornecidas pela teoria social carecem de uma reconstrução interna por parte da ciência jurídica, com base nos critérios e linguagens próprias do direito); e, por fim, (vi) naturalização disciplinar (a reconstrução interna pelo direito dos influxos normativos da teoria social não podem implicar uma desfiguração dos aspectos definidores do material original, havendo que se manter um mínimo de fidedignidade substancial).

4. Dentre os recortes teórico-sociais passíveis de serem aplicados a uma pesquisa crítico-analítica em direito penal, parecem ser especialmente promissoras as vertentes derivadas da categoria filosófica do reconhecimento. Com origens que remontam à filosofia de Fichte, o reconhecimento recebeu desenvolvimentos decisivos ao longo da obra de Hegel. A ideia de reconhecimento constitui-se originalmente em categoria filosófica de análise acerca de como as identidades pessoais se constituem de modo não-monológico, mas sim mediadas por tramas de intersubjetividade em que a autocompreensão qualitativa de um indivíduo depende de seu reconhecimento por seus pares; quer dizer, o eu reconhece a si mesmo como sujeito na medida em que é assim reconhecido e valorizado por seu ser-outro, que, igualmente, também opõe aos demais demandas por reconhecimento. Mais que isso, o reconhecimento como conceito filosófico consiste na chave de uma dinâmica relacional pela qual as relações éticas aprimoram-se de tal modo a constituir espaços mais amplos de sociabilidade, para além da mera intersubjetividade, alcançando nas instituições sociais 
formas mais estabilizadas e sofisticadas. É por isso que o reconhecimento acaba sendo introduzido por Hegel, destarte, como a base de uma proposta de filosofia política alternativa às teses liberais contratualistas, estas por ele consideradas demasiadamente erigidas sobre uma ideia de liberdade demasiadamente abstrata e de indivíduos excessivamente autocentrados, desprovidos de compromissos de mutualidade. Assim como em Hegel a noção de reconhecimento evolui desde uma dinâmica intersubjetiva, passando a se constituir em uma chave de aprimoramento das relações éticas de uma vida coletiva mais amplamente considerada, chegando a estabelecer-se finalmente como substrato ético das instituições modernas, também a teoria social realiza movimento similar ao internalizá-lo em seus debates. Daí as teorias sociais contemporâneas terem encontrado nas teses filosóficas do reconhecimento de si no outro não apenas uma possibilidade de releitura da dimensão moral dos conflitos sociais, mas também um verdadeiro critério avaliativo para uma "reconstrução normativa" das instituições e práticas sociais modernas - i.e., o desempenho efetivo e potencial destas no que concerne à viabilização do reconhecimento mútuo e a uma promoção mais estável dos valores socialmente construídos a partir dessas interações.

5. As teorias do reconhecimento apresentam poderosas orientações normativas capazes de provocar autorreflexões por parte da ciência jurídico-penal, na medida em que reposiciona questionamentos e proposições acerca dos critérios de legitimação de uma ordem social e das respectivas instituições que a corporificam. $\mathrm{O}$ reconhecimento como categoria filosófico-social funciona como relevante chave para uma análise crítica acerca de como as relações éticas e arranjos institucionais de uma determinada sociedade podem, conjugando as necessidades de proteção individual e veiculação de valores comunitários, estruturar-se com vistas a dar vazão às diversas demandas sociais abrangidas pela ideia de liberdade; e, afinal, efetivamente satisfazê-las.

6. A teoria social, nesta linha, abre espaço à utilização do reconhecimento na análise tanto de: (i) relações interindividuais (um sujeito há de reconhecer seu outro como unidade ética, dotada de direitos e deveres, autoconsciente e moralmente relevante; do contrário, em vez de práticas de subjetivação, o que se teria seriam situações de reconhecimento denegado - aqui tem-se profícua chave de análise das justificações morais subjacentes às interações vítima/ofensor); como, também, (ii) relações entre indivíduos e instituições, ou indivíduos e seu meio social (instituições legítimas dependem do quanto os sujeitos logram ver-se nelas identificados, e do desempenho delas na realização da liberdade, promoção valores comunitariamente compartilhados, além da estabilização de tramas sociais de 
reconhecimento mútuo e solidariedade - aqui, o reconhecimento emerge como poderosa ferramenta filosófica de crítica ao direito penal como ordem normativa institucionalizada).

7. A análise das justificações que fundamentam o lugar comumente atribuído à vítima nas ciências criminais indicam uma difícil compatibilidade com a ideia de reconhecimento como critério crítico-normativo. A exposição do percurso historicamente percorrido pela vítima nos discursos penais demonstrou como a superação da "neutralização da vítima" em direção a seu "redescobrimento" culminou no surgimento e consolidação da vitimologia como disciplina científica. Originalmente dedicada a compreender a dinâmica interacionista que envolve as relações da vítima com o ofensor, os estudos vitimológicos iniciais empreenderam esforços de categorização de vítimas conforme o grau e natureza de sua eventual contribuição causal com os eventos que levaram à sua própria vitimização. Para além de seus desenvolvimentos metodológicos, contudo, a história da vitimologia pode ser fundamentalmente contada adotando a ampliação de seu objeto como fio-condutor: após críticas de pesquisadores e ativistas na linha de que as análises dos estágios iniciais da pesquisa vitimológica incorriam em perigosos discursos de blaming the victim, a vitimologia experienciou uma verdadeira redefinição em suas redes teóricas e estratégias de pesquisa. Especialmente a partir dos anos 1970 e 1980, à vitimologia interessava não mais apenas as dinâmicas e interações pessoas entre vítima e ofensor na causação dos eventos delitivos: assumindo conotações mais críticas, a pesquisa vitimológica passa a se debruçar sobre as estruturas sociais que condicionam os processos de vitimização; as estratégias de atuação de vítimas em sua relação crítica com essas estruturas; as experiências individuais de vitimização; os interesses e necessidades das vítimas, conjuntamente com as respostas sociais organizadas na tentativa de atendê-los. Se é verdade que o movimento de "retorno à vítima" acabou sendo apropriado e distorcido pelos discursos políticos de law and order, é igualmente verdadeiro que a vítima foi cada vez mais compreendida como sujeito empírico, cujas experiências e necessidades individuais importam como genuíno objeto de uma pesquisa vitimológica alinhadas à reafirmação das liberdades das vítimas.

8. No que concerne às demais ciências criminais, embora o processo penal tenha se mostrado ligeiramente mais sensível a estas novas formas de compreensão da vítima de crime (gradualmente introduzindo mecanismos orientados à inclusão desta como sujeito de direitos processualmente relevante), a posição por ela ocupada nas discussões jurídicopenais não sofreu transformações exatamente animadoras. Ao contrário, a receptividade da literatura penalista às contribuições da pesquisa vitimológica limitaram-se 
fundamentalmente aos estágios iniciais desta - mais especificamente, o direito penal admitiu a formação de uma "vitimodogmática" orientada a compreender como eventuais contribuições causais da vítima para a ocorrência de um resultado danoso poderia influenciar as teorizações sobre o injusto penal ou as discussões sobre a fixação da pena. Se, por um lado a internalização dogmática do conceito de autorresponsabilidade significa imputar à vítima algum grau de capacidade moral, no sentido de gerenciar espaços pessoais liberdade e assumir as consequências de suas escolhas, o fato é que esse tímido reconhecimento da vítima como sujeito nas teses dogmático-penais se limitam a esse restrito campo de pesquisa, e apenas em teorizações voltadas a atenuar ou isentar a responsabilidade penal do ofensor. O direito penal, por outro lado, exteriorizou um franco ceticismo com relação ao desenvolvimentos posteriores da pesquisa vitimológica (os quais, como visto, atribuíram às experiências de vitimização e ao atendimento das necessidades das vítimas status de objeto de pesquisa, compreendendo a vítima ainda como sujeito empírico cuja atuação crítica perante seus interlocutores e estruturas sociais importa moral e cientificamente). Em grande parte, a desconfiança penalista se deve ao receio de ver reposicionadas nas ideias penais as práticas antigas de revanchismo e excesso punitivo; os pressupostos desse ceticismo, contudo, não podem ser generalizados e carecem de maiores precisões analíticas, especialmente a respeito da figura da vítima nos discursos securitários, da relação dos movimentos de vítimas com discursos de enrijecimento securitário e da suposta incongruência entre direitos das vítimas e do ofensor.

9. A convergência dos estudos sobre a vítima nas ciências criminais com as contribuições da teoria social acerca dos critérios de legitimação das necessidades modernas indicaram haver um déficit de reconhecimento das pessoas concretamente afetadas pelo delito. No Sistema de Justiça concretamente considerado, apesar da abertura comparativamente maior às descobertas e tendências da vitimologia, resta uma série de desafios quanto à implementação prática de inovações legislativas inclusivas já introduzidas no ordenamento jurídico-processual brasileiro; além, é fato, de pesquisas empíricas de maior abrangência sobre o grau de satisfação das vítimas como sujeitos processuais de um modelo jurisdicional predominantemente assentado em bases retributivas. Já no campo das ideias penais, a pesquisa demonstrou haver diagnósticos de uma "evaporação vitimal" decorrente da persistência das teses de neutralização nos estudos dogmáticos, havendo ainda análises no sentido de afirmar que os tradicionais conceitos de "sujeito passivo" e "ofendido" 
mascaram a realidade de sujeitos que seria, na realidade, verdadeiras "vítimas da teoria do delito" e da pena.

10. A tese dedicou-se a propor duas vias pelas quais a ideia filosófico-social de reconhecimento da vítima poderia fornecer relevantes orientações normativas ao direito penal, especialmente o desafiando cientificamente a se autocorrigir no sentido de buscar estratégias de inclusão da vítima e reconhecimento de seus interesses; sem, contudo, que isso implique uma exasperação distorcida de discursos punitivos ou uma ruptura com preceitos constitucionais de proteção dos direitos do acusado.

11. O primeiro campo de movimentação do reconhecimento diz respeito à revitalização dos desafios de legitimação democrática do direito penal como ordem jurídiconormativa, considerando-se a diversidade de demandas sociais modernamente abrigadas sob as ideias de "liberdade" e "lutas por reconhecimento". No plano vertical do reconhecimento, referente às relações vítima/instituições sociais, a posição comumente atribuída pela ordem jurídico-penal à vítima obstaculiza a criação de sentimentos de pertencimento e identificação da vítima como sujeito em instituições que, idealmente, deveriam corporificar a ideia de uma liberdade intersubjetiva juridicamente cristalizada a partir do reconhecimento. Mudanças de paradigma de um direito penal "do fato" a um direito penal "do conflito" podem sugerir interessantes caminhos para repensar os fundamentos do poder de punir e novas estratégias de restauração, mais atentas aos danos concretos experienciados pelos sujeitos envolvidos no conflito penal e mais sensíveis a suas expectativas de verem-se contemplados pelos procedimentos decisórios. Podem, ainda, proporcionar estratégias de aproximação entre vítima e ofensor por meio de mecanismos não necessariamente punitivos, em práticas de maior fomento a reconhecimentos intersubjetivos no âmbito interno das instituições.

12. A segunda via de aplicação do reconhecimento da vítima refere à interpretação filosófica dos processos intersubjetivos de imputação moral a partir das teorias do reconhecimento, com resultados que podem promover uma revisão das teses de imputação jurídico-penal; nas quais, em verdade, a vítima tradicionalmente figura como personagem periférica e de uma marginal relevância científica. Antes de uma violação da lei do Estado, de uma negação da validade da norma ou de uma ofensa a um bem jurídico-penal, o delito constitui-se em um desrespeito à vítima como sujeito, compreendido em seu sentido não psicologizante, mas filosófico: o crime é experimentado pela vítima como uma injúria moral, que afeta dimensões de sua personalidade não abrangidas pelas categorias jurídicas tradicionais. É neste ponto que as teorias do reconhecimento, dedicadas à compreensão dos 
processos de mútua consideração dos sujeitos como agentes morais, abrem espaço para uma ressignificação da reação penal e para um reemergir da vítima como sujeito também do conflito penal, com experiências individuais de sofrimento e expectativas normativas que importam para uma reinterpretação dos critérios de imputação jurídico-penal. 


\section{REFERÊNCIAS BIBLIOGRÁFICAS}

ADORNO, Sérgio. "Insegurança versus direitos humanos: entre a lei e a ordem". Tempo social, São Paulo, v. 11, n. 2, p. 129-153, out. 1999.

ALBRECHT, Peter-Alexis. La funcionalización de la víctima en el sistema de justicia penal. Trad. Luis M. Reyna Alfaro. In: SCHÜNEMANN, Bernd et al. La víctima en el sistema penal: dogmática, proceso y política criminal. Lima: Grijley, 2006, p. 39-58.

ALCÁCER GUIRAO, Rafael. "Facticidad y normatividad. Notas sobre la relación entre ciencias sociales y Derecho penal". Actualidad Penal, n. 13, p. 229-261, mar.-abr. 2001.

ALLER, Germán. El derecho penal y la víctima. Buenos Aires: B de F, 138-139.

ALVAREZ, Marcos César et al. "A vítima no processo penal brasileiro: um novo protagonismo no cenário contemporâneo?" Revista Brasileira de Ciências Criminais, São Paulo, v. 18, n. 86, p.247-288, set./out. 2010.

AMSTUTZ, Marc; FISCHER-LESCANO, Andreas (org.). Kritische Systemtheorie: Zur Evolution einer normativen Theorie. Bielefeld: Transcript, 2013.

BALZER, Nicole. Spuren der Anerkennung: Studien zu einer sozial- und erziehungswissenschaftlichen Kategorie. Wiesbaden: Springer VS, 2012.

BARKER, Vanessa. "The politics of pain: a political institutionalist analysis of crime victims' moral protests". Law \& Society Review, v. 41, n. 3, p. 619-663, 2007.

BASSIOUNI, M. Cherif. “International recognition of victims' rights”. Human Rights Law Review, v. 6, n. 2, p. 203-279, 2006.

BATESON, Regina. "Crime victimization and political participation". American Political Science Review, v. 106, n. 3, p. 570-587, ago. 2012.

BAUBÖCK, Rainer. Normative political theory and empirical research. In: DELLA PORTA, Donatella; KEATING, Michael. Approaches and methodologies in the social sciences: a pluralist perspective. Nova York: Cambride University Press, 2008.

BAUSCH, Kenneth C. The emerging consensus in social systems theory. Nova York: Springer Science, Business Media New York, 2001.

BAUSURE, Mauro. "Reificación y crítica de las patologías sociales en el marco del proyecto de teoría crítica de Axel Honneth". Enrahonar, n. 46, p. 75-91, 2011.

BECHARA, Ana Elisa Liberatore Silva. Da teoria do bem jurídico como critério de legitimidade do direito penal. Tese de Livre-Dôcencia apresentada à Faculdade de Direito da Universidade de São Paulo. São Paulo, 2010.

BENHABIB, Seyla. Critique, norm, and utopia. Nova York: Columbia University Press, 1986.

BERNARD, Jessie. "The validation of normative social theory". The Journal of Philosophy, Nova York, v. 47, n. 17, p. 489-490, ago. 1950.

BINDING, Karl. Grundriss des Deutschen Strafrecht. 8. ed. Leipzig: Felix Meiner, 1913. . Handbuch des Strafrecht, tomo 1. Leipzig: Duncker \& Humblot, 1885. 
BOBBIO, Norberto. Thomas Hobbes. Trad. Manuel Escriva de Romani. Esplugues de Llobregat, Barcelona: 1991.

BOLLENS, Scott A. "Human security through an urban lens". Journal of Human Security, v. 4, n. 3, p. 36-53, 2008.

BOLTANSKI, Luc. On critique: a sociology of emancipation. Trad, Gregory Elliott. Cambridge: Polity, 2011.

BONET ESTEVA, Margarita. La víctima del delito: la autopuesta en peligro como causa de exclusión del tipo de injusto. Madrid: Mc Graw Hill, 1999.

BOURDIEU, Pierre. Esboço de uma teoria da prática: precedido de três estudos de etnologia cabila. Trad. Miguel Serras Pereira. Oeiras: Celta, 2000.

BROOKS, Thom. Hegel's political philosophy: a systematic reading of the Philosophy of Right. Edinburgo: Edinburgh University Press, 2007.

BUSATO, Paulo Cesar. "Bases de uma teoria do delito a partir da filosofia da linguagem". Revista de Estudos Criminais, Porto Alegre, v. 10, n. 42, p. 101-121, jul./set., 2011.

CÂMARA, Guilherme Costa. Programa de política criminal - orientado para a vítima de crime. São Paulo: Editora Revista dos Tribunais, 2008.

CAMARGO, Silvio César. Modernidade e dominação: Theodor Adorno e a teoria social contemporânea. São Paulo: Annablume, Fapesp, 2006.

CAMARGO, Silvio. "Axel Honneth e o legado da teoria crítica". Politica e Trabalho, Revista de Ciências Sociais, João Pessoa, n. 24, p. 123-138, abr. 2006.

CANCIO MELIÁ, Manuel. L'adeguatezza sociale. In: PAWLIK, Michael; CORNACCHIA, Luigi. Hans Welzel nella prospectiva attuale: fondamenti filosofici sviluppi dogmatici ed esiti storici del finalismo penale. Napole: Editoriale Scientifica, 2015.

. "Reflexiones sobre la victimodogmatica en la teoria del delito". Revista Brasileira de Ciências Criminais, São Paulo, v. 7, n. 25, p. 23-57, jan./mar. 1999.

CANIVEZ, Patrice. "Pathologies of recognition". Philosophy and Social Criticism, v. 37, n. 7, p. 851-887, 2011.

CAUX, Luiz Philipe de. "Um mundo que, por acaso, não é como deveria ser: crítica e explicação em Axel Honneth". Cadernos de Ética e Filosofia Política, n. 30, p. 165$180,2017$.

CELIKATES, Robin. Karl Marx: critique as emancipatory practice. In: DE BOER, Karin; SONDEREGGER, Ruth (ed.) Conceptions of critique in modern and contemporary philosophy. Basingstoke: Pallgrave Macmillan, 2012.

. Kritik als soziale Praxis: Gesellschaftliche Selbstverständigung und kritische Theorie. Frankfurt am Main: Campus, 2009.

. "O não reconhecimento sistemático e a prática da crítica: Bourdieu, Boltanski e o papel da teoria crítica”. Novos Estudos - CEBRAP, n. 93, p. 29-42, jul. 2012.

CEOBANU, Alin M.; WOOD, Charles H.; RIBEIRO, Ludmila. Crime victimization and public support for democracy: evidence from Latin America. International Journal of Public Opinion Research, Oxford, v. 23, n. 1, p. 56-78, 2010. 
CEREZO MIR, José. "Ontologismo y normativismo en el finalismo de los años cincuenta". Revista de Derecho Penal y Criminología, v. 2, n. 12, p. 56, 2003.

CIFALI, Ana Claudia. A politica criminal brasileira no governo Lula (2003-2010): diretrizes, reformas legais. São Paulo: IBCCRIM, 2016.

CLARKE, James Alexander. "Fichte and Hegel on recognition". British Journal for the History of Philosophy, v. 17, n. 2, p. 365-385, 2009.

COTTERRELL, Roger. Law, culture and society: legal ideas in the mirror of social theory. Aldershot: Ashgate, 2006.

. "Socio-legal studies, law schools, and legal and social theory". Queen Mary School of Law, Legal Studies Research Paper No. 126/2012, 30 set. 2012.

CRAWFORD, Adam. Restorative justice and crime prevention: conceptual links and policy challenges. In: ITALIAN MINISTRY OF JUSTICE (ed.). Restorative justice and crime prevention: presenting a theoretical exploration, an empirical analysis and the policy perspective. Roma: Italian Ministry of Justice, 2010, p. 1-22.

CRESPO, Eduardo Demetrio (dir.); MAROTO CALATAYUD, Manuel (coord.). Neurociencias y derecho penal: nuevas perspectivas en el ámbito de la culpabilidad y tratamiento jurídico-penal de la periculosidad. Montevideo: B. de F., 2013.

CUAREZMA TERÁM, Sergio J. La victimología. In: PICADO S., Sonia; TRINDADE, Antônio Cançado A.; CUÉLLAR, Roberto (comp.). Estudios básicos de derechos humanos, tomo V. San José: Instituto Interamericano de Derechos Humanos, 1996, p. 296-317.

D'AVILA, Fabio Roberto. Ofensividade em direito penal: escritos sobre a teoria do crime como ofensa a bens jurídicos. Porto Alegre: Livraria do Advogado Editora, 2009.

DAHL, Gudrun. "Sociology and beyond: agency, victimisation and the ethics of writing". Asian Journal of Social Science, v. 37, p. 391-407, 2009.

DAMMERT, Lucia. Seguridad ciudadana y cohesión social en América Latina. 03 Colección de Estudios sobre Políticas Públicas Locales y Regionales de Cohesión Social. Barcelona: Programa URB-AL III, 2012.

DE LA MAZA, Luis Mariano. "El sentido del reconocimiento como formación del espíritu en Hegel”. Contrastes - Revista Internacional de Filosofia, n. 15, v. 2, p. 153-172, 2010.

DECKER, Kevin S. "Right and recognition: criminal action and intersubjectivity in Hegel's early ethics". History of Political Thought, v. 22, n. 2, p. 300-316, 2001.

DIAS, Jorge de Figueiredo. Direito penal: parte geral, tomo I - questões fundamentais; a doutrina geral do crime. Coimbra: Coimbra Editora, 2004.

DÍAZ, Elías. Sociología y filosofía del derecho. 2. ed. Madrid: Taurus, 1981.

DÍEZ RIPOLLÉS, José Luis. La racionalidad de las leyes penales: práctica y teoría. Madrid: Editorial Trotta, 2003.

DOERNER, William G; LAB, Steven P. Victimology. Burlington: Elsevier, 2012. 
DREIER, Horst. Rechtslehre, Staatssoziologie und Demokratietheorie bei Hans Kelsen. Baden-Baden: Nomos, 1986.

DUNN, Jennifer L. "The politics of empathy: social movements and victim repertoires". Sociological Focus, v. 37, n. 3, p. 235-250, ago. 2004.

DURKHEIM, Émile. As regras do método sociológico. Trad. Paulo Neves e Eduardo Brandão. 3. ed. São Paulo: Martins Fontes, 2007.

DURKHEIM, Émile. Da divisão social do trabalho. Trad. Eduardo Brandão. 2. ed. São Paulo: Martins Fontes, 1999.

DUSSICH, John P. J. "The evolution of international victimology and its current status in the world today". Revista de Victimología/Journal of Victimology, v.1, n. 1, p. 37-81, 2015.

DUSSICH, John P. J. Victimology - past, present and future. $131^{\text {st }}$ International Senior Seminar Visiting Expert's Papers, Resource Material Series n. 70. Tokyo: UNAFEI, 2006, p. 116-129.

EMMERS, Jo-Anne. Introduction à la victimologie. Nouvelle édition [on-line]. Montreal: Presses de l'Université de Montréal, 2003. Disponível em: $<$ http://books.openedition.org/pum/10762>. Acesso em: 08 jan. 2019.

ESER, Albin. Acerca del renacimiento de la víctima en el procedimiento penal. Tendencias nacionales e internacionales. Trad. Fabricio O. Guariglia e Fernando J. Córdoba. In: ESER, Albin; HIRSCH, Hans; ROXIN, Claus et al. De los delitos y de las víctimas. Buenos Aires: Ad-Hoc, 1992, p. 13-52.

. "Funktionswandel strafrechtlicher Prozeßmaximen: Auf dem Weg zur ,Reprivatisierung' des Strafverfahrens?". Zeitschrift für die gesamte Strafrechtswissenschaft, v. 104, n. 2, p. 361-397, 1992.

. "Una justicia penal a la medida del ser humano: visión de un sistema penal y procesal orientado al ser humano como individuo y ser social". Trad. Jon Mirena Lana Gorostiza. Revista de Derecho Penal y Criminología, Madrid, n. 1, p. 131-152, jan. 1998.

FATTAH, Ezzat A. The need for a critical victimology. In: FATTAH, Ezzat A. (ed.) Towards a critical victimology. Londres: The MacMillan Press, 1992, p. 3-26.

. The United Nations Declaration of Basic Principles of Justice for Victims of Crime and Abuse of Power: a constructive critique. In: FATTAH, Ezzat A. (ed.) Towards a critical victimology. Londres: Macmillan Press, 1992, p. 401-424.

. "Victimology: past, present and future". Criminologie, v. 33, n. 1, p. 17-46, 2000.

FEIJÓO SÁNCHEZ, Bernardo José. "Derecho penal y neurociencias: una relación tormentosa?". Revista peruana de ciencias penales, Lima, n. 24, p. 253-326, 2012.

FEINBERG, Joel. The expressive function of punishment. In: TONRY, Michael (ed.). Why punish? How much? A reader on punishment. Nova York: Oxford University Press, 2011.

FERGUNSON, Claire; TURVEY, Brent E. Victimology: a brief history with an introduction to forensic victimology. In: TURVEY, Brent E.; WAYNE, Petherick (ed.) Forensic 
victimology: examining violent crime victims in investigative and legal contexts. San Diego: Elsevier, Academic Press, 2009, p. 1-32.

FERNANDES, Antonio Scarance. Processo penal constitucional. 6. ed. rev., atual. e ampl. São Paulo: Editora Revista dos Tribunais, 2010.

- Reavaliação do papel da vítima no processo criminal. Tese de livre-docência apresentada à Faculdade de Direito da Universidade de São Paulo - FD/USP. São Paulo, set. 1993.

FERNANDES, Fernando Andrade. Sobre uma opção jurídico-política e jurídicometodológica de compreensão das ciências jurídico-criminais. In: ANDRADE, Manuel da Costa. Liber discipulorum para Jorge de Figueiredo Dias. Coimbra: Coimbra Editora, 2003, p. 53-83.

FERNANDES, Valéria Diez Scarance. O papel do processo penal na proteção da vítima. In: VAZ, Denise Provasi et al (org.) Eficiência e garantismo no processo penal: estudos em homenagem a Antonio Scarance Fernandes. São Paulo: LiberArs, 2017, p. 17-32.

FERRAZ JUNIOR, Tercio Sampaio. Introdução ao estudo do direito: técnica, decisão, dominação. 4. ed. rev. e ampl. São Paulo: Atlas, 2003.

FERREIRO BAAMONDE, Xulio. La víctima en el proceso penal. Madrid: La Ley, 2005.

FERRI, Enrico. Sociología criminal, tomo II. Trad. Antonio Soto y Hernández. Madrid: Centro Editorial de Góngora, 1913.

FICHTE, Johann Gottlieb. Foundations of natural right-according to the Principles of the Wissenschaftslehre. Trad. Michael Baur e ed. Frederick Neuhouser. Cambridge: Cambridge University Press, 2000.

FLETCHER, George P. El lugar de las víctimas en la teoria de la retribución. Trad. Luis M. Reyna Alfaro. In: SCHÜNEMANN, Bernd et al. (org.). La víctima en el sistema penal: dogmática, proceso y política criminal. Lima: Editora Jurídica Grijley, 2006, p. 85100 .

FLETCHER, George P. La dogmática jurídico-penal alemana vista desde fuera. In: ESER, Albin; HASSEMER, Winfried; BURKHARDT, Björn (org.). La ciencia del derecho penal ante el nuevo milenio. Versão espanhola organizada por Francisco Muñoz Conde. Valencia: Tirant lo Blanch, 2004.

FORST, Rainer. Contextos da justiça: filosofia política para além de liberalismo e comunitarismo. São Paulo: Boitempo, 2010.

FOUCAULT, Michel. Nietzsche, a genealogia e a história. In: MICHEL, Foucault. Microfísica do poder. Org. e trad. Roberto Machado. Rio de Janeiro: Edições Graal, 1997.

FRANCO, Alberto Silva. Crimes hediondos. 4. ed. rev., atual. e ampl. São Paulo: Editora Revista dos Tribunais, 2000.

FRASER, Nancy. Social justice in the age of identity politics: redistribution, recognition, and participation. In: FRASER, Nancy; HONNETH, Axel. Redistribution or recognition? A political-philosophical Exchange. Trad. Joel Golb, James Ingram e Christiane Wilke. Londres: Verso, p. 7-109. 
FREITAS, Marisa Helena D’Arbo Alves de. Proteção legal das vítimas de crimes no direito brasileiro. In: FREITAS, Marisa Helena D'Arbo Alves de; FALEIROS JUNIOR, Roberto Galvão (org.) Estudos contemporâneos de vitimologia. São Paulo: Cultura Acadêmica, 2011, p. 9-24.

FRISCH, Wolfgang. Bien jurídico, derecho, estructura del delito e imputación en el contexto de la legitimación de la pena estatal. Trad. Ricardo Robes Planas. In: HEFENDEHL, Roland (ed.). La teoría del bien jurídico: ¿Fundamento de legitimación del derecho penal o juego de abalorios dogmáticos? Organização da edição espanhola por Rafael Alcácer, María Martín e Iñigo Ortiz de Urbina. Madrid: Marcial Pons, 2007.

FRISCH, Wolfgang. Tipo penal e imputación objetiva. Trad. Manuel Cancio Melía et al. Madrid: Editorial Colex, 1995.

FRISCH, Wolfgang. Wesenzüge rechtswissenschaftlichen Arbeitens - am Beispiel und aus der Sicht des Strafrechts. In: ENGEL, Christoph; SCHÖN, Wolfgang. Das Propium der Rechtswissenschaft. Tübingen: Mohr Siebeck, 2007.

FROMMEL, Monika. "Opferschutz durch hohe Strafdrohungen - Der vergiftete Apfel vom Baume des Punitivismus". Monatsschrift für Kriminologie und Strafrechtreform, v. 68, p. 350-360, 1985.

FULDAN, Hans Friedrich. Das Recht der Philosophie in Hegels Philosophie des Rechts. Frankfurt am Main: Vittorio Klostermann, 1968.

GALDINO, Danielle de Souza. Proteção pela metade: um estudo sobre as necessidades humanas no Programa Federal de Assistência a Vítimas e Testemunhas Ameaçadas. Dissertação de Mestrado apresentada ao Instituto de Ciências Humanas da Universidade de Brasília. Brasília, 2013.

GARCÍA-PABLOS DE MOLINA, Antonio. Introducción al derecho penal: instituciones, fundamentos y tendencias del derecho penal, v. 1. 5. ed. Madrid: Centro de Estudios Ramón Aceres, 2012.

GARLAND, David. La cultura del control: crimen y orden social en la sociedad contemporánea. Trad. Máximo Sozzo. Barcelona: Editorial Gedisa, 2005.

GARLAND, Tammy. "Mendelson, Beniamin”. In: WILSON, Janet K. (ed.) The Praeger handbook of victimology. Santa Barbara: ABC-CLIO, 2009.

GIEHARKE, Katrin. Der Zusammenhang von Freiheit, Sicherheit und Strafe im Recht: eine Untersuchung zu den Grundlagen und Kriterien legitimer Terrorismusprävention. Berlin: Duncker\&Humblot, 2013.

GRACIA MARTÍN, Luis. "El finalismo como método sintético real-normativo para la construcción de la teoría del delito". Revista Electrónica de Ciencia Penal y Criminología, n. 06-07, p. 07:1-07:22, 2004.

GRECO, Luís. Introdução à dogmática funcionalista do delito: em comemoração aos trinta anos de Política criminal e sistema jurídico-penal de Roxin. Revista Brasileira de Ciências Criminais, São Paulo, v. 8, n. 32, out./dez., 2000.

GRIMM, Dieter (org.). Rechtswissenschaft und Nachbarwissenschaften. Frankfurt am Main: Athenäum Fischer Taschenbuch, 1974. 
GROENHUIJSEN, Marc S. Conflicts of victims' interests and offenders' rights in the criminal justice system: A European perspective. In: SUMMER C. (ed.) International victimology: selected papers from the 8th International Symposium. Canberra: Australian Institute of Criminology, 1996, p. 163-176.

GÜNTHER, Frieder. "The neglect of Hans Kelsen in west German public law scholarship, 1945-1980". In: TELMAN, D. A. Jeremy. Hans Kelsen in America: selective affinities and the mysteries of academic influence. Basileia: Springer, 2016.

GÜNTHER, Klaus. "Criminal law, crime and punishment as communication". Normative Orders Working Papers 02/2014. Cluster of Excelence at Goethe University Frankfurt/Main, 2014.

. Die symbolisch-expressive Bedeutung der Strafe: eine neue Straftheorie jenseits von Vergeltung und Prävention. In: PRITTWITZ, Klaus; BAURMANN, Michael; GÜNTHER, Klaus (org.). Festschrift für Klaus Lüderssen. Baden-Baden: Nomos Verlag, 2002.

. Ein Modell legitimen Scheiterns. Der Kampf um Anerkennung als Opfer. In: HONNETH, Axel; LINDEMANN, Ophelia; VOSWINKEL, Stephan (org.) Strukturwandel der Anerkennung: Paradoxien sozialer Integration in der Gegenwart. Frankfurt am Main: Campus Verlag, 2013, p. 185-248.

. Qual o conceito de pessoa de que necessita a teoria do discurso do direito? Reflexões sobre a conexão interna entre pessoa deliberativa, cidadão e pessoa de direito. In: PÜSCHEL, Flavia Portella; MACHADO, Marta Rodriguez de Assis. Teoria da responsabilidade no Estado democrático de direito: textos de Klaus Günther. São Paulo: Saraiva, 2009, p. 27-52.

. Responsabilização na sociedade civil. In: PÜSCHEL, Flavia Portella; MACHADO, Marta Rodriguez de Assis. Teoria da responsabilidade no Estado democrático de direito: textos de Klaus Günther. São Paulo: Saraiva, 2009, p. 1-26.

HABERMAS, Jürgen. Consciência moral e agir comunicativo. Trad. Guido A. de Almeida. Rio de Janeiro: Tempo Brasileiro, 2003.

. Direito e democracia: entre facticidade e validade, v. 2. Trad. Flávio Beno Siebeneichler. Rio de Janeiro: Tempo Brasileiro, 1997.

. Direito e democracia: entre facticidade e validade, v. 1. Trad. Flávio Beno Siebeneichler. Rio de Janeiro: Tempo Brasileiro, 1997.

. "From Kant to Hegel and back again - the move towards detranscendentalization". European Journal of Philosphy, v. 7, n. 2, p. 129-157, ago. 1999.

. Para a reconstrução do materialismo histórico. Trad. Carlos Nelson Coutinho. São Paulo: Editora Brasiliense, 1983.

. Reconstruction and interpretation in the social sciences. In: HABERMAS, Jürgen. Moral consciousness and communicative action. Trad. Christian Lenhardt e Shierry Weber Nicholsen. Cambridge: Polity, 1990, p. 21-42.

. Reply to my critics. Trad. Ciaran Cronin. In: INLAYSON, James Gordon; FREYENHAGEN, Fabian (ed.). Habermas and Rawls: disputing the political. Nova York: Routledge, 2011, p. 283-304. 
- Teoria do agir comunicativo: sobre a crítica da razão funcionalista. Trad. Flávio Beno Siebeneichler. São Paulo: Editora WMF Martins Fontes, 2012.

. The theory of communicative action, v. 2. Lifeworld and system: a critique of functionalist reason. Trad. Thomas McCarthy. Boston: Beacon Press, 1987.

. Theorie der Gesellschaft oder Sozialtechnologie? In: HABERMAS, Jürgen; LUHMANN, Niklas. Theorie der Gesellschaft oder Sozialtechnologie: was leistet die Systemforschung? Frankfurt am Main: Surkhamp, 1971, p. 142-290.

HANDLER, Joel F. Social movements and the legal system: a theory of law reform and social change. New York, San Francisco, London: Academic Press, 1978.

HARRINGTON, Austin. What is social theory? In: HARRINGTON, Austin (ed.). Modern social theory: an introduction. Oxford: Oxford University Press, 2005.

HARRIS, H. S. "Hegelianism of the 'right' and 'left"'. The Review of Metaphysics, v. 11, n. 4, p. 603-609, jun. 1958.

. The concept of recognition in Hegel's Jena Manuscripts. In: O’NEILL, John (ed.). Hegel's dialectics of desire and recognition: texts and commentary. Albany: State University of New York Press, 1996, p. 233-252.

HASSEMER, Raimund. Schutzbedürftigkeit des Opfers und Strafrechtsdogmatik: Zugeich ein Beitrag zur Auslegung des Irrtumsmerkmals in §263 StGB. Berlim: Duncker \& Humblot, 1981.

HASSEMER, Winfried. Fundamentos del derecho penal. Trad. Francisco Muñoz Conde e Luis Arroyo Zapatero. Barcelona: Bosch, 1984.

. La autocomprensión de la ciencia del derecho penal frente a las exigencias de su tiempo. Trad. $\mathrm{M}^{\mathrm{a}}$ del Mar Díaz Pita. In: ESER, Albin; HASSEMER, Winfried; BURKHARDT, Björn (org.). La ciencia del derecho penal ante el nuevo milenio. Versão espanhola organizada por Francisco Muñoz Conde. Valencia: Tirant lo Blanch, 2004.

. "Neurociências e culpabilidade em direito penal". Revista Brasileira de Ciências Criminais, São Paulo, v. 21, n. 100, p. 211-226, jan./fev. 2013.

- ¿Por qué castigar? Razones por las que merece la pena la pena. Trad. Manuel Cancio Meliá e Francisco Muñoz Conde. Valencia: Tirant lo Blanch, 2016.

(org.). Sozialwissenschaften im Strafrecht: Fälle und Lösungen in Ausbildung und Prüfung. Darmstadt: Luchterhand, 1984.

; LÜDERSSEN, Klaus; NAUCKE, Wolfgang. Fortschritte im Strafrecht durch die Sozialwissenschaften? Heidelberg: C. F. Müller Juristischer Verlag, 1983.

; REEMTSMA, Jan Phillip. Verbrechensopfer: Gesetz und Gerechtigkeit. Munich: C.H. Beck, 2002.

HAYM, Rudolf. Hegel und seine Zeit. 2. ed. Hildesheim: Georg Olms Verlagsbuchhandlung, 1962.

HEGEL, G.W.F. Enciclopedia de las ciencias filosóficas. Trad. Ramón Valls Plana. Madrid: Alianza Editorial, 1997. 
. Fenomenologia do espírito. Trad. Paulo Meneses. 2. ed. Rio de Janeiro: Editora Vozes, Universidade de São Francisco, 2003.

Filosofía real. Trad. José María Ripalda. 2. ed. Madrid: Fondo de Cultura Económica de España e Universidad Nacional de Educación a Distancia, 2006.

Princípios da filosofia do direito. Trad. Orlando Vitorino. São Paulo: Martins Fontes, 1997.

Sistema da vida ética. Trad. Artur Morão. Lisboa: Edições 70, 1991.

System of ethical life (1802/03) and first philosophy of spirit (part III of the System of speculative philosophy). Trad. e ed. H. S. Harris e T. M. Knox. Albany: State University of New York Press, 1979.

The Berlin phenomenology.Trad. M. J. Petry. Dordrecht: D. Reidel Publishing Company, 1981.

Vorlesungen über die Philosophie des Rechts. Berlin 1819/1820. Org. Emil Angehrn, Martin Bondeli e Hoo Nam Seelmann. Hamburgo: Felix Meiner Verlag, 2000.

Vorlesungen über Rechtsphilosophie 1818-1831: Dritter Band. Edição e comentários de Karl-Heinz Ilting. Stuttgart: Frommann-Holzboog, 1973.

Princípios da filosofia do direito. Trad. Orlando Vitorino. São Paulo: Martins Fontes, 1997.

HELDRICH, Andreas. "Das Trojanische Pferd in der Zitadelle des Rechts?". Juristische Schulung-JuS, v. 14, p. 280-288, 1974.

HERMAN, Lawrence; STRANG, Heather. Restorative justice: the evidence. Londres: The Smith Institute, 2007.

HERNÁNDEZ-PACHECO, Javier. “Arte, religión, filosofía. La doble posible interpretación del Espíritu Absoluto en G.W.F. Hegel”. Contrastes - Revista Internacional de Filosofía, Universidad de Málaga, v. XXII, n. 2, p. 153-164, 2017.

HERRERA MORENO, Myriam. "Humanización social y luz victimológica”. Eguzkilore: Cuaderno del Instituto Vasco de Criminología, San Sebastián, n. 26, p.73-85, 2012. . La hora de la víctima: compendio de victimología. Madrid: Edersa, 1996.

"Sobre los orígenes científicos de la victimología". Cuadernos de política criminal, Madrid, n. 56, p. 481-517, 1995.

HILGENDORF, Eric. "Bedingungen gelingender Interdisziplinarität - am Beispiel der Rechtswissenschaft”. Juristen Zeitung - JZ, v. 65, n. 19, p. 917, 2010.

; SCHULZE-FIELITZ, Helmuth. Rechtswissenschaft im Prozess der Selbstreflexion. In: HILGENDORF, Erich; SCHULZE-FIELITZ, Helmuth (org.). Selbstreflexion der Rechtswissenschaft. Tübingen: Mohr Siebeck, 2015.

HILLENKAMP, Thomas. The influence of victim behaviour on the dogmatic judgment of the offence: some remarks on the relationship between victimology and the dogmatics of penal law. In: MIYAZAWA, Koichi; OHYA, Minoru (ed.) Victimology in comparative perspective: papers given at the "Fourth International Symposium on Victimology" 1982 in Tokyo-Kyoto. Tokyo: Seibundo Publishing, 1986, p. 111-124. 
HIRSCH, Hans Joachim. "Internationalisierung des Strafrechts und Strafrechtswissenschaft: nationale und universale Strafrechtswissenschaft". Zeitschrift für die gesamte Strafrechtswissenschaft-ZStW, v. 16, n. 4, p. 835-854, 2004.

HOBBES, Thomas. Leviatã. Trad. João Paulo Monteiro e Maria Beatriz Nizza da Silva. Organização de Richard Tuck. São Paulo: Martins Fontes, 2008.

HÖFFE, Ottfried. Lexikon der Ethik. 7. ed. rev. e ampl. Munique: C. H. Beck, 2008.

HOFFMANN-RIEM, Wolfgang. "Forschung im Schnittfeld von Rechts- und Sozialwissenschaften als Aufgabe. Zum Sinn des neuen,Preises Recht und Gesellschaft““. Zeitschrift für Rechtssoziologie, n. 19, v. 1, p. 1-7, 1998.

. Zur Verwendungstauglichkeit der Sozialwissenschaften für die Juristenausbildung. In: HOFFMANN-RIEM, Wolfgang (org.). Offene Rechtswissenschaft: ausgewählte Schriften und begleitende Analysen. Tübingen: Mohr Siebeck, 2010.

. Zwischenschritte zur Modernisierung der Rechtswissenschaft. Juristen Zeitung, n. 13, p, 645-652, jul. 2007.

HOFMANN, Martin Ludwig. Monopole der Gewalt: Mafiose Macht, staatliche Souveränität und die Wiederkehr normativer Theorie. Bielefeld: transcript-Verlag, 2015.

HOLTON, Robert J. Teoria social clássica. In: TURNER, Bryan S. (ed.). Teoria social. Algés: Difusão Editorial, 2002.

HONNETH, Axel. Anerkennung: eine europäische Ideengeschichte. Frankfurt: Surkhamp, 2018.

. El derecho de la libertad: esbozo de una eticidad democrática. Trad. Graciela Calderón. Madrid: Clave Intelectual; Buenos Aires: Katz Editores, 2014.

. From desire to recognition: Hegel's account of human sociality. In: MOYAR, Dean; QUANTE, Michael (ed.) Hegel's phenomenology of spirit: a critical guide. Cambridge: Cambridge University Press, 2008, p. 76-90.

. Gerechtigkeitstheorie als Gesellschaftsanalyse: Überlegungen im Anschluss an Hegel. In: MENKE, Christoph; REBENTISCH, Juliano (org.). Axel Honneth: Gerechtigkeit und Gesellschaft. Postdamer Seminar. Berlim: Berliner WissenschaftsVerlag, 2008, p. 11-33.

. Justice as institutionalized freedom. A Hegelian perspective. In: SORENSEN, Asger; RAFFNSOE-MOLLER, Morten; GRON, Arne (org.) Dialectics, self-consciousness, and recognition: the Hegelian legacy. Malmö: NSU Press, 2009, p. 171-200.

. Luta por reconhecimento: a gramática moral dos conflitos sociais. Trad. Luiz Repa. São Paulo: Editora 34, 2003.

. Moral consciousness and class domination: some problems in the analysis of hidden morality. Trad. Mitchel G. Ash. In: HONNETH, Axel. Disrespect: the normative foundations of critical theory. Cambridge: Polity Press, 2007, p. 80-96.

. "Grounding recognition: a rejoinder to critical questions". Trad. Joel Anderson. Inquiry: an Interdisciplinary Journal of Philosophy, v. 45, n. 4, p. 499-520, 2002.

- Pathologies of the social. In: HONNETH, Axel. Disrespect: the normative foundations of critical theory. Cambridge: Polity Press, 2007. 
. Reconstructive social criticism with a genealogical proviso: on the idea of "critique" in the Frankfurt school. In: HONNETH, Axel. Pathologies of reason: on the legacy of critical theory. Trad. James Ingram et al. Nova York: Columbia University Press, p. 43-53.

. Redistribution as recognition: a response to Nancy Fraser. In: FRASER, Nancy; HONNETH, Axel. Redistribution or recognition? A political-philosophical exchange. Trad. Joel Golb, James Ingram e Christiane Wilke. Londres: Verso, 2003, p. 129-134.

. "Rekonstruktive Gesellschaftskritik unter genealogischem Vorbehalt. Zur Idee der "Kritik" in der Frankfurter Schule". Deutsche Zeitschrift für Philosophie - DZPhil, Berlim, v. 48, n. 5, p. 729-737, 2000.

. Sofrimento de indeterminação: uma reatualização da filosofia de direito de Hegel. Trad. Rúrion Soares de Melo. São Paulo: Editora Singular, 2007.

; BOLTANSKI, Luc; CELIKATES, Robin. Sociology of critique or critical theory? Luc Boltanski and Axel Honneth in conversation with Robin Celikates. Trad. Simon Susen. In: SUSEN, Simon; TURNER, Bryan S. (ed.). The spirit of Luc Boltanski: essays on the "pragmatic sociology of critique". Londres: Anthem, 2014.

HORKHEIMER, Max. "A presente situação da filosofia social e as tarefas de um Instituto de Pesquisas Sociais. Trad. Isabel M. Loureiro e Carlos E. Jordão. Praga-Revista de Estudos Marxistas, São Paulo, n. 7, p. 121-132, mar. 1999.

; ADORNO, Theodor W. Dialéctica de la ilustración: fragmentos filosóficos. Trad. Juan José Sánchez. 3. ed. Madrid: Editorial Trotta, 1998.

HÖRNLE, Tatjana. "Distribution of punishment: the role of a victim's perspective". Buffalo Criminal Law Review, v. 3, n. 1, p. 175-209, abr. 1999.

HORSTER, Detlef. Sozialphilosophie. Stuttgart: Philipp Reclam, 2012 [Edição Kindle].

HOULGATE, Stephen. Hegel's Phenomenology of Spirit: a reader's guide. Londres: Bloomsbury Academic, 2013. . The Hegel Reader. Malden: Blackwell Publishing, 1998.

IFERGAN, Pini. Hegel's discovery of the spirit. Autonomy, alienation and ethical life: the Jena lectures 1802-1806. Trad. Nessa Olshansky-Ashtar. Houndmills: Palgrave MacMillan, 2014.

ILTING, Karl-Heinz. The structure of Hegel's 'Philosophy of Right'. In PEŁCZYŃSKI, Zbigniew A. (ed.) Hegel's political philosophy: problems and perspectives. Cambridge: Cambridge University Press, 1971, p. 90-110.

ISENSEE, Josef. Das Grundrecht auf Sicherheit: zu den Schutzpflichten des freiheitlichen Verfassungsstaates. Berlim, Nova York: Walter de Gruyter, 1983.

ISER, Mattias. Empörung und Fortschritt: Grundlagen einer kritischen Theorie der Gesellschaft. Frankfurt am Main: Campus, 2008.

; STRECKER, David. Jürgen Habermas zur Einführung. Starnberg: Surkhamp, 2010.

IVALDO, Marco. "Doutrina da ciência e filosofia transcendental: Fichte em face de Kant". Trad. Agemir Bavaresco et al. Revista de Estud(i)os sobre Fichte, n. 5, p. 1-8, 2012. 
JAEGGI, Rahel; CELIKATES, Robin. Sozialphilosophie: eine Einführung. Munique: C. H. Beck, 2017.

; WESCHE; Tilo. Einführung: Was ist Kritik? In: JAEGGI, Rahel; WESCHE; Tilo (org.). Was ist Kritik? Frankfurt am Main: Surkhamp, 2009.

JAESCHKE, Walter. Direito e eticidade. Trad. Peter Naumann. Porto Alegre: EDIPUCRS, 2004.

. Hegel Handbuch: Leben - Werk - Schule. 3. ed. Stuttgart: Metzler, 2016.

- Subjetividade e intersubjetividade na filosofia clássica alemã. Trad. Márcia Gonçalves. In: JAESCHKE, Walter. Direito e eticidade. Porto Alegre: EDIPUCRS, 2004.

JAKOBS, Günther. "La ciencia del derecho penal ante las exigencias del presente". Revista peruana de ciencias penales, Lima, v. 7/8, n. 12, p. 303-320, 2002.

. La imputación objetiva en el derecho penal. Trad. Manuel Cancio Melía. Buenos Aires: Ad Hoc, 1996.

. Sociedad, norma y persona en una teoría de un Derecho penal funcional. Trad. de Manuel Cancio Meliá y Bernardo Feiióo Sánchez. Madrid: Civitas, 2000.

- Strafrecht als wissenschaftliche Disziplin. In: ENGEL, Christoph; SCHÖN, Wolfgang. Das Propium der Rechtswissenschaft. Tübingen: Mohr Siebeck, 2007.

JARDIM, Afrânio Silva. Crítica à ação penal subsidiária e à ação penal popular subsidiária. In: JARDIM, Afrânio Silva. Direito processual penal. Rio de Janeiro: Forense, 2005, p. 293-301.

JELLINEK, Georg. Teoría general del estado. Trad. Fernando de los Ríos. México, D.F.: Fondo de Cultura Económica, 2000.

JENNINGS, Will et al. "Penal populism and the public thermostat: crime, punitiveness, and public policy". Governance: an International Journal of Policy, Administration, and institutions, v. 30, n. 3, p. 463-481, jul. 2017.

JEREZ, Miguel. Los grupos de presión. In: DEL ÁGUILA, Rafael (coord.). Manual de ciencia política. 5. ed. Madrid: Editorial Trotta, 2008, p. 295-297.

JESTAEDT, Matthias. "A ciência como visão de mundo: ciência do direito e concepção de democracia em Hans Kelsen". Trad. Carlos Eduardo de Abreu Boucault. Revista Brasileira de Estudos Políticos, Belo Horizonte, n. 106, p. 30-33, jan./jun. 2013.

. "Öffentliches Recht" als wissenschaftliche Disziplin. In: ENGEL, Christoph; SCHÖN, Wolfgang (org.). Das Propium der Rechtswissenschaft. Tübingen: Mohr Siebeck, 2007.

. Perspektiven der Rechtswissenschaftstheorie. In: JESTAEDT, Matthias; LEPSIUS, Oliver (org.). Rechtswissenschaftstheorie. Tübingen: Mohr Siebeck, 2008.

. Rechtswissenschaft als normative Disziplin: Banalität, Komplexität und Brisanz der Klassifikationsfrage. In: KIRSTE, Stephan. Interdisziplinarität in den Rechtswissenschaften: ein interdisziplinärer und internationaler Dialog. Berlim: Dunckler \& Humblot, 2016. 
JOAS, Hans; KNÖBL, Wolfgang. Social theory: twenty introductory lectures. Trad. Alex Skinner. Nova York: Cambridge University Press, 2009.

JONES, Trevor; NEWBURN, Tim. "Three strikes and you're out: exploring symbol and substance in American and British crime control politics". British Journal of Criminology, v. 46, n. 5, p. 781-802, 2006.

JOSÉ SÁNCHEZ, Juan. Introducción - Sentido y alcance de la Ilustración. In: HORKHEIMER, Max; ADORNO, Theodor W. Dialéctica de la ilustración: fragmentos filosóficos. Trad. Juan José Sánchez. 3. ed. Madrid: Editorial Trotta, 1998.

JOSIFOVIC, Sasa. The dialectic of normative atitudes in Hegel's lordship and bondage. In: KRIJNEN, Christian. Recognition - German idealism as an ongoing challenge. Leiden: Brill, 2014, p. 267-286.

KAIN, Philip J. Hegel on the other: a study of the Phenomenology of the Spirit. Albany: State University of New York Press, 2005.

KARMEN, Andrew J. "Who's against victims' rights? The nature of the opposition to provictim initiatives in criminal justice". Journal of Civil Rights and Economic Development, v. 8, n. 1, p. 157-175, 1992.

KELSEN, Hans. General theory of norms. Trad. Michael Hartney. Nova York: Oxford University Press, 1991. . Teoría pura del derecho. Trad. Moisés Nilve. 4. ed. Buenos Aires: Eudeba, 1960.

KILCHLING, Michael. Opferinteressen und Strafverfolgung. Freiburg im Breisgrau: Ed. iuscrim, Max-Planck Institut für Ausländliches und Internationales Strafrecht, 1995.

. Opferschutz innerhalb und außerhalb des Strafrechts: Perspektiven zur Übertragung opferscützender Normen aus dem Strafverfahrensrecht in andere Verfahrensordnungen. Berlim: Duncker \& Humblot, 2018.

KING, Anna; MARUNA, Sadd. Is a conservative just a liberal who has been mugged? Punishment \& Society, n. 11, 137-169, 2009.

KIRSTE, Stephan. Voraussetzungen von Interdisziplinarität der Rechtswissenschaften. In: KIRSTE, Stephan. Interdisziplinarität in den Rechtswissenschaften: ein interdisziplinärer und internationaler Dialog. Berlim: Dunckler \& Humblot, 2016.

KLECK, Gary; JACKSON, Dylan Baker. "Does crime cause punitiveness?" Crime \& Delinquency, v. 63, n. 12, p. 1572-1599, 2017.

KLEIN, Julie Thompson. A taxonomy of interdisciplinarity. In: FRODEMAN, Robert (ed.). The Oxford handbook of interdisciplinarity. Nova York: Oxford University Press.

KLOC-KONKOŁOWICZ, Jakub. Anerkennung bei Hegel. In: SIEP, Ludwig; IKAHEIMO, H.; QUANTE, Michael (ed.). Handbuch Anerkennung. Springer Reference Geisteswissenschaften. Wiesbaden: Springer, 2018.

KÖHLER, Thomas. Die Konflikttheorie der Anerkennungstheorie. In: BONACKER, Thorsten (org.) Sozialwissenschaftliche Konflikttheorien: eine Einführung. Opladen: Leske + Budrich, 2002. 
KOK, Arthur. The metaphysics of recognition: on Hegel's concept of self-consciouness in the Phenomenology of Spirit. In: KRIJNEN, Christian. Recognition - German idealism as an ongoing challenge. Leiden: Brill, 2014, p. 67-99.

LADWIG, Bern. Von sicheren Rechten zum Recht auf Sicherheit? In: ABELS, Gabriele (org.). Vorsicht Sicherheit! Legitimationsprobleme der Ordnung der Freiheit. BadenBaden: Nomos, 2016, p. 81-98.

LAITINEN, Arto; SÄRKELÄ, Arvi; AIKÄHEIMO, Heikki. "Pathologies of recognition: an introduction”. Studies in Social and Political Thought, v. 25, p. 3-24, 2015.

LASK, Emil. Gesammelte Schriften, v. 1. Organização de Eugen Herrigel. Tubingen: Mohr Siebeck, 1923.

LAUTMANN, Rüdiger. Soziologie vor den Toren der Jurisprudenz: zur Kooperation der beiden Disziplinen. Stuttgart: W. Kohlhammer, 1971.

LENK, Klaus. "Von der Bedeutung der Rechtswissenschaft und der Sozialwissenschaften für Juristen". Kritische Justiz, v. 3, n. 3, p. 273-282, 1970.

LESCANO-FISCHER, Andreas. "A teoria dos sistemas da Escola de Frankfurt". Trad. Rúrion Melo. Novos Estudos-CEBRAP, n. 86, p. 163-177, mar. 2010.

LIMA, Erick Cordeiro de. "O conceito hegeliano de direito na filosofia do espírito de 1805/06”. Veritas, Porto Alegre, v. 55, n. 3, p. 130-177, set./dez. 2010.

. "O fragmento 22 dos Jenaer Systementwürfe (1803/04): apresentação e tradução". Revista Eletrônica Estudos Hegelianos, ano 5, n. 8, p. 75-98, jun. 2008.

- "Movimento de consciência e eticidade: para uma localização da 'filosofia do espírito’ de 1803/1804”. Revista de Filosofia Aurora, v. 20, n. 26, p. , jan./jun. 2008.

LINDEMANN, Gesa. „Die Emergenzfunktion und die konstitutive Funktion des Dritten. Perspektiven einer kritisch-systematischen Theorieentwicklung“. Zeitschrift für Soziologie, v. 35, n. 2, p. 83, abr. 2006.

LOICK, Daniel. "Juridification and politics: from the dilema of juridification to the paradoxe of rights". Philosophy and Social Criticism, v. 40 (8), p. 757-778, 2014.

LOOS, Fritz. "Die Funktion der Sozialwissenschaften in der Juristenausbildung". Zeitschrift für Rechtspolitik, v. 7, n. 7, p. 162, jul. 1974.

LÓPEZ HERNÁNDEZ, José. "El pensamiento político del joven Hegel”. Anales de Derecho, Universidad de Murcia, v. 27, p. 66-91, 2009.

LOSANO, Mario G. Introdução. Trad. Ivone Castilho Benedetti. In: KELSEN, Hans. $O$ problema da justiça. Trad. João Baptista Machado. São Paulo: Martins Fontes, 1998.

LUZÓN PEÑA, Diego-Manuel. Principio de alteridad o de identidad vs. principio de autorresponsabilidad. Participación em autopuesta em peligro, heteropuesta em peligro. consentida y equivalencia: el criterio del control del riesgo. Revista Nuevo Foro Penal, Medelin, v. 6, jan.-jun. 2010.

MACHADO, Marta Rodriguez de Assis; PÜSCHEL, Flávia Portella. "Klaus Günther: culpa penal no Estado democrático de direito". In: NOBRE, Marcos (org.). Curso livre de teoria crítica. 3. ed. Campinas, SP: Papirus, 2013. 
MAHLMANN, Christian. Die Strafrechtswissenschaft der DDR: Klassenkampftheorie und Verbrechenslehre. Frankfurt am Main: Peter Lang, 2002.

MAIER, Julio B. J. La vítima y el sistema penal. In: ESER, Abin et al. (ed.) De los delitos y de las víctimas. Buenos Aires: Editorial Ad-Hoc, 1992, p. 183-249.

MANTOVANI, Fernando. Diritto penale: parte generale. 9. ed. Pádua: Cedam, 2015.

MARCUSE, Herbert. Razão e revolução: Hegel e o advento da teoria social. Trad. Marília Barroso. São Paulo: Paz e Terra, 2004.

MARTIKAINEN, Ossi. The principle of the subjectivity and Sittlichkeit in Hegel's Philosophy of Right. In: KOTKAVIRTA, Jussi (ed.) Right, morality, ethical life: studies in G.W.F. Hegel's Philosophy of Right. Jyväskylä: SoPhi Academic Press, 1997, p. 93-105.

MARTUCCELLI, Danilo. "La teoria social y la renovación de las preguntas sociológicas". Papeles de la CEIC - Centro de Estudios sobre la Identidad Colectiva, Universidad del País Vasco, v. 2009-2, v. 2, p. 1-2, set. 2009.

; SORJ, Bernardo. O desafio latino-americano: coesão social e democracia. Rio de Janeiro: Civilização Brasileira, 2008.

MARX, Karl. Manuscritos econômico-filosóficos. Trad. Jesus Ranieri. São Paulo: Boitempo, 2004.

. O capital: crítica da economia política. Livro I: o processo de produção do capital. Trad. Rubens Enderle. São Paulo: Boitempo, 2013.

. O capital: crítica da economia política. Livro II: o processo de circulação do capital. Trad. Rubens Enderle. São Paulo: Boitempo, 2014.

O capital: crítica da economia política. Livro III: o processo global da produção capitalista. Trad. Rubens Enderle. São Paulo: Boitempo, 2017.

MATUS ACUÑA, Jean Pierre. "Víctima, idealismo y neopunitivismo en el derecho penal internacional”. Revista Nuevo Foro Penal, v. 8, n. 81, p. 139-145, jul./dez. 2013.

MAWBY, R.I.; WALKLATE, S. Critical victimology: international perspectives. Londres: Sage Publications, 1994.

MCALINDEN, Anne-Marie. "Deconstructing victim and offender identities in discourses on child sexual abuse: hierarchies, blame and the good/evil dialectic". The British Journal of Criminology, v. 54, n. 2, p. 180-198, mar. 2014.

MEAD, George Herbert. Mind, self, and society from the standpoint of a social behaviorist. Chicago: The University of Chicago Press, 1974.

MENDOZA BUERGO, Blanca. El derecho penal en la sociedad del riesgo. Madrid: Civitas, 2001.

MENKE, Christoph. Kritik der Rechte. Berlim: Suhrkamp, 2015.

MEYER, Frank. "Eine Geologie des Strafrechts". Zeitschrift für die gesamte Strafrechtswissenschaft, v. 123, n.1, p. 1-46, 2011.

MIERS, David. "Positivist victimology: a critique". International Review of Victimology, v. 1, n. 1, p. 3-22, 1989. 
MILISAVLJEVIĆ, Viladmir. "The struggle for recognition in Hegel's Jena Writings". Journal of Legal and Social Sciences: Annals of the Faculty of Law in Belgrade, International Edition, p. 133-150, 2007.

MIR PUIG, Santiago. Derecho penal: parte general. 9. ed. Barcelona: Reppertor, 2011.

. Sobre la posibilidad y límites de una ciencia social del derecho penal. In: MIR PUIG, Santiago (org.). Derecho penal y ciencias sociales. Belaterra: Universidade Autónoma de Barcelona, 1982.

MOBLEY, Alan. Ressuscitating justice through the human security framework: are we ready to listen? In: LAWRENCE, Keith O. Race, crime and punishment: breaking the connection in America. Washington D.C.: The Aspen Institute, 2011, p. 103-120.

MÖLLER, Kolja. "Crítica do direito e teoria dos sistemas”. Trad. Patrícia da Silva Santos. Tempo Social - Revista de Sociologia da USP, v. 27, n. 2, p. 129-152, 2015.

MOLLNAU, Karl A. Empirische Sozialerkenntnis und Rechtswissenschaft. In: KAMENKA, Eugene; SUMMERS, Robert S.; TWINING, William L. (ed.). Soziologische Jurisprudenz und realistische Theorien des Rechts. Berlim: Duncker \& Humblot, 1986.

MONCADA, Luís Cabral de. Prefácio. In: RADBRUCH, Gustav. Filosofia do direito. Trad. Luís Cabral de Moncada. Coimbra: Tipologia Minerva, 1934.

MUÑOZ CONDE, Francisco. Introducción al derecho penal. Buenos Aires: Editorial B de F, 2001.

NAUCKE, Wolfgang. Über die juristische Relevanz der Sozialwissenschaften. Frankfurt am Main: Alfred Metzner, 1972.

NEUHOUSER, Frederick. Desire, recognition, and the relation between bondsman and lord. In: WESTPHAL, Ken R. (ed.) The Blackwell guide to Hegel's phenomenology of spirit. Oxford: Willey-Blackwell, 2009, p. 37-54.

. Foundations of Hegel's social theory: actualizing freedom. Cambridge: Harvard University Press.

NEUMANN, Ulfrid. Wissenschaftstheorie der Rechtswissenschaft bei Hans Kelsen und Gustav Radbruch. Zwei "neukantinische" Perspektiven. In: PAULSON, Stanley L.; STOLLEIS, Michael (org.). Hans Kelsen: Staatsrechtslehrer und Rechtstheoretiker des 20. Jahrhunderts. Tübingen: Mohr Siebeck, 2005.

NEVES, Marcelo. Entre Têmis e Leviatã: uma relação difícil: o Estado democrático de direito a partir e além de Luhmann e Habermas. 2. ed. São Paulo: Martins Fontes, 2008 .

NOBRE, Marcos. "Teoria crítica: uma nova geração”. Novos estudos - CEBRAP, São Paulo, n. 93, p. 23-27, jul. 2012.

- Apresentação - Luta por reconhecimento: Axel Honneth e a teoria crítica. In: HONNETH, Axel. Luta por reconhecimento: a gramática moral dos conflitos sociais. Trad. Luiz Repa. São Paulo: Editora 34, 2003.

. Reconstrução em dois níveis: um aspecto do modelo crítico de Axel Honneth. In: MELO, Rurión (coord.). A teoria crítica de Axel Honneth: reconhecimento, liberdade e justiça. São Paulo: Saraiva, 2013 [Edição Kindle]. 
; REPA, Luiz. Introdução - Reconstruindo Habermas: etapas e sentidos de um percurso. In: NOBRE, Marcos; REPA, Luiz (org.). Habermas e a reconstrução: sobre a categoria central da teoria crítica habermasiana. Campinas-SP: Papirus, 2012.

NOGUERA, José Antonio. La teoría crítica: de Frankfurt a Habermas. Una “traducción' de la teoría de la acción comunicativa a la sociología. Papers, n. 50, 1996.

NONET, Philippe; SELZNICK, Philip. Law and transition: toward responsive law. Nova York: Octagon Books, 1978.

NORBERT, Elias. The civilizing process: sociogenetic and psychogenetic investigations. Trad. Edmund Jephcott. ed. rev. Oxford: Blackwell Publishing, 2000.

OLIVEIRA, Edmundo. Vitimologia e direito penal: crime precipitado ou programado pela vítima. Curitiba: Juruá, 2018.

OLIVEIRA, Robespierre de. O papel da filosofia na teoria crítica de Herbert Marcuse. São Paulo: Editora Unesp, 2012, p. 23 e ss. (especialmente nota de rodapé no 2).

OLIVER, Kelly. Witnessing: beyond recognition. Minneapolis: University of Minnesota Press, 2001.

PATEMAN, Carole. Participação e teoria democrática. Trad. Luiz Paulo Rouanet. Rio de Janeiro: Paz e Terra, 1992.

PAVARINI, Massimo. Gobierno del miedo o a través del miedo? In: Máximo Sozzo (org.). Por una sociología crítica del control social: ensayos en honor a Juan S. Pegoraro. Ciudad Autónoma de Buenos Aires: Del Puerto, 2010.

PAVČNIK, Marijan. "Methodological clarity or substantial purity of law? Notes on the discussion between Kelsen and Pitamic". Ratio Juris, v. 27, n. 2, p. 176-189, jun. 2014.

PAWLIK, Michael. "O terrorista e o direito dele: sobre a posição teórico-jurídica do terrorismo moderno". Trad. Eduardo Saad-Diniz. In: PAWLIK, Michael. Teoria da ciência do direito penal, filosofia e terrorismo. São Paulo: LiberArs, 2012, p. 109-144.

. Staatlicher Strafanspruch und Strafzwecke. In: SCHUMANN, Eva (org.) Das strafende Gesetz im sozialen Rechtsstaat: 15. Symposium der Kommission „Die Funktion des Gesetzes in Geschichte und Gegenwart“. Berlin: De Gruyter, 2010, p. 59-93.

. "Teoría de la ciencia del derecho penal". Trad. Eduardo Saad-Diniz e Cecília Marcela Ugartemendía. Cuadernos de Política Criminal, v. 2, n. 106, p. 5-34, abr. 2012.

. Ciudadanía y derecho penal: fundamentos de la teoría de la pena y del delito en un Estado de libertades. Trad. Ricardo Robles Planas et al. Barcelona: Atelier, 2016.

. Hegel e a racionalidade do real. Trad. Eduardo Saad-Diniz. In: PAWLIK, Michael. Teoria da ciência do direito penal, filosofia e terrorismo. Trad. e org. Eduardo SaadDiniz. São Paulo: LiberArs, 2012.

PEDERSEN, Jørgen. "Habermas and the political sciences: the relationship between theory and practice". Philosophy of the Social Sciences, v. 39, n. 3, p. 381-407, set. 2009.

- Habermas' method: rational reconstruction. Tese de Doutorado (Filosofia) Universidade de Bergen. Bergen, 2011, p. 15-16. Disponível em: $<$ http://bora.uib.no/>. Acesso em: 15 mai. 2018. 
PEMBERTON, Antony. Victim movements: from diversified needs to varying criminal justice agendas. Acta Criminologica, v. 22, n. 3, p. 1-23, 2009.

PÉREZ CEPEDA, Ana Isabel. La seguridad como fundamento de la deriva del derecho penal postmoderno. Madrid: Iustel, 2007.

PETHERBRIDGE, Danielle. The critical theory of Axel Honneth. Plymouth: Lexington Books, 2013.

PINKARD, Terry. "Virtues, morality, and Sittlichkeit: from maxims to practice". European Journal of Philosophy, v. 7, n. 2, p. 217-239, ago. 1999.

. "What is the non-metaphysical reading of Hegel? A reply to Frederick Beiser". Hegel Bulletin, v. 17, n. 2, p. 13-20, 1996.

PINTO, José Marcelino de Rezende. A teoria da ação comunicativa de Jürgen Habermas: conceitos básicos e possibilidades de aplicação à administração escolar. Paidéia, Faculdade de Filosofia, Ciências e Letras de Ribeirão Preto da USP, n. 89, ago. 1995.

PIPPIN, Robert B. Die Aktualität des Deutschen Idealismus. Berlin: Surkhamp Verlag, 2016.

. Hegel on self-consciousness: desire and death in the Phenomenology of Spirit. Princeton: Princeton University Press, 2011.

. "What is the question for which Hegel's theory of recognition is the answer?" European Journal of Philosophy, Oxford, v. 8, n. 2, p. 155-172, 2000.

PIRES, Álvaro. La formation de la rationalité pénale moderne aus XVIII ${ }^{\mathrm{e}}$ siècle. In: DEBUYST, Christian; DIGNEFFE, Françoise; PIRES, Álvaro P. Histoire des savoirs sur le crime et la peine, v. 2: la rationalité pénale et la naissance de la criminologie. Bruxelas: Larcier, 2008, p. 21-76.

POLAINO NAVERRETE, Miguel; POLAINO-ORTS, Miguel. Imputación normativa: exposición programática en casos fundamentales. In: ROXIN, Claus; POLAINO NAVARRETE, Miguel; POLAINO-ORTS, Miguel. Política criminal y dogmática penal. Lima: Ara Editores, 2013.

POLAINO-ORTS, Miguel. "Vigencia de la norma: el potencial de sentido de un concepto". In: MONTEALEGRE LYNETT, Eduardo. El funcionalismo en derecho penal: libro homenaje al Profesor Günther Jakobs, tomo II. Bogotá: Universidad Externado de Colombia, 2003.

POPPER, Karl. A sociedade aberta e seus inimigos, vol. 2. Trad. Milton Amado. Belo Horizonte: Editora Itatiaia; São Paulo: Editora Universidade de São Paulo, 1974.

PRADA LONDOÑO, Manuel Alejandro. "La idea de reconocimiento en el Hegel de Jena. Una lectura con Paul Ricoeur”. Franciscanum, n. 164, v. LVIII, p. 21-45, 2015.

PRITTWITZ, Cornelius. "The resurrection of the victim in penal theory". Buffalo Criminal Law Review, v. 3, n. 1, p. 109-129, abr. 1999.

. Strafrecht und Risiko: Untersuchungen zur Krise von Strafrecht und Kriminalpolitik in der Risikogesellschaft. Frankfurt am Main: Vittorio Klostermann, 1993, p. 81-127.

PYYHTINEN, Olli. Simmel and 'the social'. Basingstoke: Palgrave Macmillan, 2010. 
QUANTE, Michael. La realtà dello spirito. Trad. Giovanna Miolli e Frederico Sanguinetti. Milão: Franco Angeli, 2016.

QUANTE, Michael; SCHWEIKARD, David P. “'Leading a universal life': the systematic relevance of Hegel's social philosophy". History of the Human Sciences, v. 22, n. 1, p. 58-78, 2009.

QUANTE, Michael. "The pure notion of recognition": reflections on the grammar of the relation of recognition in Hegel's Phenomenology of Spirit. In: SCHMIDT AM BUSCH, Hans-Christoph; ZURN, Christopher F. (ed.). The philosophy of recognition: historical and contemporary perspectives. Plymouth: Lexington Books, 2010.

QUINNEY, Richard. “Who is the victim?”. Criminology, p. 314-323, nov. 1972 (p.321).

RADBRUCH, Gustav. Filosofia do direito. Trad. Luís Cabral de Moncada. Coimbra: Tipologia Minerva, 1934.

RECKWITZ, Andreas. Kreativität und soziale Praxis: Studien zur Sozial- und Gesellschaftstheorie. Bielefeld: Transcript Verlag, 2016.

REDDING, Paul. "Georg Wilhelm Friedrich Hegel". The Stanford Encyclopedia of Philosophy, Summer 2018 Edition. Disponível em: <https://plato.stanford.edu/>. Acesso em: 09 dez. 2018.

. The independence and dependence of self-consciousness: the dialectic of lord and bondsman in Hegel'sPhenomenology of Spirit. In: BEISER, Frederick C. (ed.) The Cambridge companion to Hegel and nineteenth-century philosophy. Cambridge: Cambridge University Press, 2008, p. 94-110.

REPA, Luiz. "Compreensões de reconstrução: sobre a noção de crítica reconstrutiva em Habermas e Celikates". Trans/Form/Ação, Marília-SP, v. 40, n. 3, p. 9-28, jul.-set., 2017.

RICOEUR, Paul. Percurso do reconhecimento. Trad. Nicolás Nyime Campanário. São Paulo: Edições Loyola, 2006.

RIGHT, Martin. Justice for victims and offenders: a restorative response to crime. 2. ed. Winchester: Waterside Press, 1996.

RIZZI, Lino. "Punir et reconnaître: distinction et implication de l'obligation juridique et du devoir éthique chez Hegel". Archives de Philosophie, Paris, v. 66, n. 2, 2003, p. 237250.

ROBLES PLANAS, Ricardo. "La identidad de la dogmática jurídico-penal". Zeitschrift für Internationale Strafrechtsdogmatik - ZIS, v. 5, n. 2, p. 62-166, 2010.

ROCKMORE, Tom. Introduction. In: ROCKMORE, Tom; BREAZEALE, Daniel (ed.). Fichte and transcendental philosophy. Houndmills: Palgrave MacMillan, 2014.

RODRÍGUEZ, Víctor Gabriel de Oliveira. Livre arbitrio e direito penal: revisão frente aos aportes da neurociência e à evolução dogmática. São Paulo: Marcial Pons, 2018.

ROGGE, Wibke. Die Entwicklung des Anerkennungsbegriffs bei Hegel. In: ASMUTH, Christoph (org.) Transzendentalphilosophie und Person: Leiblichkeit Interpersonalität - Anerkennung. Bielefeld: Transcript, 2007. 
ROSENBERG, Alexander. Philosophy of social Science. 3. ed. Filadélfia: Westview Press, 2008, p. 227-229.

ROSENFIELD, Cinara L.; SAAVEDRA, Giovani Agostini. "Reconhecimento, teoria crítica e sociedade: sobre desenvolvimento da obra de Axel Honneth e os desafios de sua aplicação no Brasil”. Sociologias, Porto Alegre, ano 15, n. 33, p. 14-54, mai./ago. 2013.

ROUSSEAU, Jean-Jacques. Discurso sobre a origem e os fundamentos da desigualdade entre os homens. Trad. Maria Ermantina Galvão. 2. ed. São Paulo: Martins Fontes, 1999.

ROXIN, Claus. Derecho penal: parte general, tomo I. Fundamentos. La estructura de la teoría del delito. Trad. Diego-Manuel Luzón Peña, Miguel Díaz y García Conlledo e Javier de Vicente Remesal. 2. ed. Madrid: Editorial Civitas, 1997, p. 386-402.

. La imputación objetiva en su significado para la teoría del tipo penal. Trad. Miguel Polaino-Orts. In: ROXIN, Claus; POLAINO NAVARRETE, Miguel; POLAINOORTS, Miguel (org.). Política criminal y dogmática penal. Lima: Ara Editores, 2013.

. Política criminal y estructura del delito. Trad. Juan Bustos Ramírez e Hernán Hormazábal Malarée. Barcelona: PPU, 1992.

ROZENWEIG, Franz. Hegel e o Estado. Trad. Ricardo Timm de Souza. São Paulo: Perspectiva, 2008.

RYAN, William. Blaming the victim. Nova York: Vintage Books, 1976.

SAAD-DINIZ, Eduardo. "Fronteras del normativismo: a ejemplo de las funciones de la información em los programas de criminal compliance". Revista da Faculdade de Direito da Universidade de São Paulo, v. 108, p. 415-441, jan.-dez. 2013.

. Inimigo e pessoa no direito penal. São Paulo: LiberArs, 2012.

. O lugar da vítima nas ciências criminais como estratégia de pesquisa. In: SAADDINIZ, Eduardo. O lugar da vítima nas ciências criminais. São Paulo: LiberArs, 2007.

. Risco nuclear. Boletim IBCCRIM, São Paulo, v. 19, n. 224, p. 12-13, jul. 2011.

. Vitimologia corporativa: um novo campo de pesquisa nas ciências criminais. Tese de Livre-docência apresentada à Faculdade de Direito de Ribeirão Preto da Universidade de São Paulo. Ribeirão Preto, fev. 2018.

; MARIN, Gustavo de Carvalho. "Imputación moral orientada a la víctima como problema de imputación objetiva". Revista de Derecho Penal, Buenos Aires: Editorial Rubinzal, p.87-116, 2016.

SAFATLE, Vladimir. "É racional parar de dialogar". Folha de S. Paulo, São Paulo, 10 mar. 2017. Disponível em: <https://www1.folha.uol.com.br>. Acesso em 10 fev. 2018.

. Grande hotel abismo: por uma reconstrução da teoria do reconhecimento. São Paulo: Editora WMF Martins Fontes, 2012.

SALIGER, Frank. Intra- und Interdisziplinarität: wie kommt das Neue in die Rechtswissenschaft? In: HILGENDORF, Eric; SCHULZE-FIELITZ, Helmuth (org.). Selbstreflexion der Rechtswissenschaft. Tübingen: Mohr Siebeck, 2015. 
SALVADOR NETTO, Alamiro Velludo. Finalidades da pena: conceito material de delito e sistema penal integral. São Paulo: Quartier Latin, 2009.

SAUER, Wilhelm. Einführung in die Rechtsphilosophie: für Unterricht und Praxis. 2. ed. Berlim: Duncker \& Humblot, 1961.

SAUER, Wilhelm. Juristische Methodenlehre: zugleich eine Einleitung in die Methodik der Geisteswissenschaften. Stuttgart: Ferdinand Enke, 1940.

SAUTNER, Lyane. Opferinteressen und Strafrechtstheorien: Zugleich ein Beitrag zum restorativen Umgang mit Straftaten. Innsbruck: Studien Verlag, 2010.

SAVAGE, Stephen P.; CHARMAN, Sarah. Public protectionism and "Sara's Law": exerting pressure through single issue campaigns. In: NASH, Mike; WILLIAMS, Andy (ed.). Handbook of public protection. Nova York: Willan Publishing, 2010, p. 434-453.

SCHAUB, Jörg. "Misdevelopments, pathologies, and normative revolutions: normative reconstruction as a method of critical theory". Critical Horizons, v. 16, n. 2, p. 107130, mai. 2015.

SCHELSKY, Helmut. "Nutzen und Gefahren der sozialwissenschaftlichen Ausbildung von Juristen”. Juristen Zeitung, v. 29, n. 13, p. 410-416, 05 jul. 1974.

SCHIEMANN, Carolin Fleury. Die Berücksichtigung von Opferinteressen in der Straftheorie. Hamburg: Dr. Kovač, 2015.

SCHMIDT, James. "Recent Hegel literature the Jena period and the Phenomenology of Spirit”. Telos, Boston University, n. 48, p. 114-142, 1981.

. „Das Verbrechensopfer im Sozialprozeß: Fortschritte der Viktimologie-Forschung“. JuristenZeitung - JZ, v. 32, n. 19, p. 620-632, out. 1977.

SCHNEIDER, Hans Joachim. Introduction: the present situation of victimology in the world. In: SCHNEIDER, Hans Joachim (ed.) The victim in international perspective: papers and essays given at the "Third International Symposium on Victimology" 1979 in Münster/Westfalia. Berlin: Walter de Gruyter, 1982, p. 11-39.

. "Kriminologie 2000: Neue Theorieansätze und ihre empirische Bestätigung". JuristenZeitung - JZ, v. 55, n. 8, p. 387-394, abr. 2000.

."Victimological developments in the world during the past three decades: a study of comparative victimology - part 2". International Journal of Offender Therapy and Comparative Criminology, v. 45, n. 5, p. 539-555, 2001.

SCHULZ, Joachim. Die Strafrechtsdogmatik nach dem Ende der vor- und außerjuristischen Gerechtigkeit. In: ENGEL, Christoph; SCHÖN, Wolfgang (org.). Das Proprium der Rechtswissenschaft. Tübingen: Mohr Siebeck, 2007.

SCHÜNEMANN, Bernd. "El sistema del ilícito jurídico-penal: concepto de bien jurídico y victimodogmática como enlace entre el sistema de la parte general y la parte especial". Revista de Derecho Penal, Buenos Aires, n. 1, p.97-133, 2003.

. Sistema del derecho penal y victimodogmática. Trad. Mariana Sacher. In: DÍEZ RIPOLLÉS, José Luis; ROMEO CASABONA, Carlos María; CRACIA MARTÍN, Luis et al. (ed.). La ciencia del derecho penal ante el nuevo siglo: libro homenaje al Profesor Doctor Don José Cerezo Mir. Madrid: Editorial Tecnos, 2002. 
SCHÜNEMANN, Hans-Wilhelm. Sozialwissenschaften und Jurisprudenz: eine Einführung für Praktiker. Munique: C. H. Beck, 1976.

SCHUSTER, Peter. Konkurriende Konfliktslösungsmöglichkeiten: Dynamyk und Grenzen des öffentlichen Strafanspruchs im Spättmittelalter. In: LÜDERSSEN, Klaus (org.) Die Durchsetzung des öffentlichen Strafanspruchs:Systematisierung der Fragestellung. Colônia: Böhlau, 2002.

SCOTT, John. Social theory: central issues in sociology. Londres: Sage Publications, 2006.

SEBBA, Leslie; BERENBLUM, Tamar. "Victimology and the sociology of new disciplines: a research agenda". International Review of Victimology, v. 20, n. 1, p. 7-30, 2014.

SEELMANN, Kurt. "Paradoxien der Opferorientierung im Strafrecht". JuristenZeitung JZ, v. 44, n. 14, p. 670-676, jul. 1989.

. Rechtsphilosophie. 5. ed. Munich: C.H. Beck, 2010.

SEVERI, Fabiana Cristina. Enfrentamento à violência contra as mulheres e a domesticação da Lei Maria da Penha: elementos do projeto jurídico feminista no Brasil. Tese de Livre-Docência apresentada à Faculdade de Direito de Ribeirão Preto da Universidade de São Paulo. Ribeirão Preto-SP, 2017.

SHERMAN, Lawrence; STRANG, Heather. "Repairing the harm: victims and restorative justice". Utah Law Review, n. 1, p. 15-42, 2003.

; _. Restorative justice to reduce victimization. In: WELSH, Brandon C.; FARRINGTON, David P. (ed.). Preventing crime: what works for children, offenders, victims and places. Nova York: Springer, 2007, p. 147-160.

SHPUNGIN, Elaine. The fluidity of victimhood. In: GAVRIELIDES, Theo (ed.). A victimled criminal justice system: addressing the paradox. Londres: Independent Academic Research Studies (IARS), 2014, p. 21-40.

SIEP, Ludwig. Anerkennung als Prinzip der praktischen Philosophie: Untersuchungen zu Hegels Jenaer Philosophie des Geistes. Hamburgo: Felix Meiner Verlag, 2014. [n.p. Edição Kindle].

. Einleitung (1979). In: SIEP, Ludwig. Anerkennung als Prinzip der praktischen Philosophie: Untersuchung zu Hegels Jenaer Philosophie des Geistes. Hamburg: Meiner, 2014.

. Hegels's Phenomenology of Spirit. Trad. Daniel Smyth. Cambridge: Cambridge University Press, 2014.

. How modern is the Hegelian State? In: JAMES, David (ed.) Hegel's elements of the philosophy of right: a critical guide. Cambridge: Cambridge University Press, 2017, p. 197-218.

. "La lucha por el reconocimiento. La relación entre Hegel y Hobbes en los escritos de Jena". Trad. Damián Rosanovich. Estudios de Filosofía, Editorial Universidad de Antioquia, n. 43, p. 31-84, 2011.

. "Sobre la actualidad de la teoría del reconocimiento de Hegel". Trad. Damián Rosanovich. Cuadernos de Filosofía, n. 63, p. 5-22, 2014. 
. Vernunftrecht und Rechtsgeschichte: Kontext und Konzept der Grundlinien im Blick auf die Vorrede. In: HEGEL, G.W.F. Grundlinien der Philosophie des Rechts. Org. Ludwig Siep. Berlim: Akdaemie Verlag, 1997, p. 5-30.

SILVA NETO, Wilson Levy Braga da. Teoria democrática e reconhecimento. Curitiba: Juruá, 2012.

SILVA SÁNCHEZ, Jesús María. Aproximación al derecho penal contemporâneo. Barcelona: J.M. Bosch, 1992.

- "Del derecho abstracto al derecho "real"”. InDret - Revista para el Análisis del Derecho, n. 4/2006. Disponível em: < http://www.indret.com/pdf/377_es.pdf $>$. Acesso em: 10 jan. 2018.

."La 'victimo-dogmática en el derecho extranjero". In: BERISTAIN IPIÑA, Antonio (dir.) Victimología: VIII Cursos de Verano en San Sebastián. San Sebastián: Servicio Editorial de la Universidad del País Vasco, 1990, p. 105-112.

. "La consideración del comportamiento de la víctima en la teoría jurídica del delito". Revista Brasileira de Ciências Criminais, São Paulo, v. 9, n. 34, p. 163-194, abr./jun. 2001.

- "Retos científicos y retos políticos de la ciencia del derecho penal". Revista de Derecho Penal y Criminología, v. 2, n. 9, p. 83-101, 2002.

. "Una crítica a las doctrinas penales de la 'lucha contra la impunidad' y del 'derecho de la víctima al castigo del autor'”. Revista de Estudios de la Justicia, Santiago, n. 11, p. 35-56, 2009.

; VARELA, Lorena. Responsabilidades individuales en estructuras de empresa: la influencia de sesgos cognitivos y dinámicas de grupo. In: SILVA SÁNCHEZ, JesúsMaría (dir.); MONTANER FERNÁNDEZ, Raquel (coord.). Criminalidad de empresa y compliance: prevención y reacciones corporativas. Barcelona: Atelier, 2013.

SHECAIRA, Sérgio Salomão. Criminologia. 3. ed. rev. atual. e ampl. São Paulo: Revista dos Tribunais, 2011.

SILVA, Matheus Pelegrino da. "A critical analysis of the philosophical-political element of the master-slave dialectic". Trans/Form/Ação, Marília, v. 38, n. 3, p. 9-24, dez. 2015.

SILVEIRA, Renato de Mello Jorge. Direito penal econômico como direito penal de perigo. São Paulo: Editora Revista dos Tribunais, 2006.

. Direito penal sexual: bases críticas para a reforma do direito penal sexual. São Paulo: Quartier Latin, 2008.

SIMON, Jonathan. Governing through crime: how the war on crime transformed American democracy and created a culture of fear. Nova York: Oxford University Press, 2007.

SINNERBRINK, Robert. Understanding Hegelianism. Stocksfield: Acumen, 2007.

SKJELSBÆK, Inger. "Victim and survivor: narrated social identities of women who experienced rape during the war in Bosnia-Herzegovina". Feminism \& Psychology, v. 16, n. 4, p. 373-403, 2006. 
SOBOTKA, Emil. "Liberdade, reconhecimento e emancipação: raízes da teoria da justiça de Axel Honneth". Sociologias, Porto Alegre, ano 15, n. 33, p. 142-168, mai./ago. 2013.

SOUZA, Jessé. "Uma teoria critica do reconhecimento". Lua Nova, São Paulo, n. 50, p. 133-158, 2000.

STAHL, Titus. “Anerkennung, Subjekitivität und Gesellschaftskritik”. Deutsche Zeitschrift für Philosophie, v. 62, n. 2, p. 239-259, 2014.

STONE, Alison. Gender, the family, and the organic State in Hegel's political thought. In: BROOKS, Thom (ed.). Hegel's philosophy of right. Oxford: Blackwell Publising, 2012, p. 143-164.

STRYDOM, Piet. “Review Essay: Honneth's sociological turn”. European Journal of Social Theory, v. 16, n. 4, p. 530-542, 2013.

TAMARIT SUMALLA, Josep M $\mathrm{M}^{\mathrm{a}}$ ¿ ¿Hasta que punto cabe pensar victimológicamente el sistema penal? In: TAMÁRIT SUMALLA, Josep $\mathrm{M}^{\mathrm{a}}$. (coord.) Estudios de victimología: actas del I Congreso Español de Victimología. Valencia: Tirant lo Blanch, 2005, p. 27-45.

. Los derechos de las víctimas. In: TAMARIT SUMALLA, Josep $\mathrm{M}^{\mathrm{a}}$ (coord.); VILLACAMPA ESTIARTE, Carolina; SERRANO MASIP, Mercedes. El estatuto de las víctimas de delitos: comentarios a la Ley 4/2015. Valencia: Tirant lo Blanch, 2015.

TAYLOR, Charles. Hegel e a sociedade moderna. Trad. Luciana Pudenzi. São Paulo: Edições Loyola, 2005.

.Hegel: sistema, método e estrutura. Trad. Nélio Schneider. São Paulo: É Realizações Editora, 2014.

TELLO NAVARRO, Felipe Hernán. "Las esferas de reconocimiento en la teoría de Axel Honneth". Revista de Sociología, Universidad de Chile, n. 26, p; 45-57, jan. 2011.

TEMPLETON, Laura J. "Emotions about crime and attitudes to punishment". Punishment \& Society, v. 14, n. 4, p. 452-474, 2012;

TESTA, Italo. Attractors of recognition. In: TESTA, Italo; RUGGIU, Luigi (ed.) "I that is we, we that is I". Perspectives on contemporary Hegel: social ontology, recognition, naturalism, and the critique of kantian constructivism. Leiden; Boston: Brill, 2016, p. 230-249.

TEUBNER, Gunther. "Altera pars audiatur: law in the collision of discourses". Trad. Klauz Ziegert e Ros Ziegert. In: RAWLINGS, Richard (ed.). Law, society and economy. Frankfurt: Oxford University Press, 1997.

. "De collisione discursuum: communicative rationalities in law, morality, and politics". Cardozo Law Review, v. 17, 1995-1996, p. 901-918.

. "Direito e teoria social: três problemas". Trad. Patricia da Silva Santos. Tempo Social, São Paulo, v. 27, n. 2, p. 77-81, dez. 2015.

. El derecho como sistema autopoiético de la sociedad global. Trad. Manuel Cancio Meliá e Carlos Gómez-Jara Díez. Lima: ARA Editores, 2005. . „Recht und Sozialtheorie: Drei Probleme“. Ancilla Iuris, p. 183-222, 31 out. 2014. 
; BOUCQUEY, Nathalie. "Pour une épistemologie constructiviste du droit". Annales. Histoire, Sciences Sociales, v. 47, n. 6, p. 1149-1150, dez. 1992.

TIMMER, Doug A.; NORMAN, William H. "The ideology of victim precipitation". Criminal Justice Review, v. 9, n. 2, p. 63-68, set. 1984.

TONRY, Michael. The costly consequences of populist posturing: ASBOs, victims, 'rebalancing' and diminution in support for civil liberties. Punishment \& Society, v. 12, n. 4, p. 387-413, 2010.

TURK, Austin T. Law as a weapon in social conflict. In: McCANN, Michael. Law and social movements. Aldershot: Ashgate Publishing, 2006.

TURNER, Bryan S. A new agenda for Social Theory? In: TURNER, Bryan S. The New Blackwell Companion to social theory. Oxford: Blackwell Publishing, 2009. . Introdução. In: TURNER, Bryan S. (ed.). Teoria social. Algés: Difusão Editorial, 2002, p. 1-18.

UN. Human security in theory and practice: an overview of the human security concept and the United Nations Trust Fund for Human Security. Publicação do United Nations Human Security Unit, 2009.

UNDP. Human development report 1994. Nova York: Oxford University Press, 1994.

URBINA GIMENO, Íñigo Ortiz. La excusa del positivismo: la presunta superación del "positivismo" y el "formalismo" por la dogmática penal contemporánea. Cizur Menor (Navarra): Thomson-Civitas, 2007.

VAN DJIK, Jan J. M. Introducing victimology. In: VAN DJIK, Jan J. M.; VAN KAAM, Ron G. H.; WEMMERS, JoAnne (eds.) Caring for crime victims: selected proceedings of the 9th International Symposium on Victimology. Monsey: Criminal Justice Press, 1999, p. 1-12.

VERWEYEN, Hansjürgen. Recht und Sittlichkeit in J.G. Fichtes Gesellschaftslehre. Munique: Karl Alber, 1975.

VILARES, Fernanda Regina. "O consenso habermasiano no processo penal: justiça penal consensual e o princípio da oportunidade nos crimes tributários". Revista Brasileira de Ciências Criminais, São Paulo, v. 20, n. 98, p. 317-338, set./out., 2012.

VIVES ANTÓN, Tomás S. Fundamentos del sistema penal: acción significativa y derechos constitucionales. 2. ed. Valencia: Tirant lo Blanch, 2011.

VOGEL, Joachim. "Derecho penal y globalización". Trad. Manuel Cancio Melliá. Anuario de la Facultad de Derecho de la Universidad Autónoma d Madrid, n. 9, p. 117, 2005.

. "Legislación penal y ciencia del derecho penal: reflexiones sobre una doctrina teórico-discursiva de la legislación penal". Revista de Derecho Penal y Criminología, v. 2, n. 11, p. 249-265, 2003.

VOIROL, Olivier. "A esfera pública e as lutas por reconhecimento: de Habermas a Honneth". Revista da Faculdade de Direito da Universidade de São Paulo, n. 11, jan.jun.2008.

VOIROL, Olivier. "Teoria crítica e pesquisa social: da dialética à reconstrução". Trad. Bruno Simões. Novos Estudos, n. 93, p. 81-99, jul. 2012. 
VON LISZT, Franz. La idea de fin en el derecho penal: programa de la Universidad de Marburgo, 1882. Trad. Carlos Pérez del Valle. Granada: Comares, 1995.

WALKLATE, Sandra. Can there be a feminist victimology? In: DAVIES, Pamela; FRANCIS, Peter; JUPP, Victor (ed.) Victimisation: theory, research and policy. Nova York: Palgrave Macmillan, 2003, p. 28-45.

WEBER, Max. Conceitos básicos de sociologia. Trad. Rubens Eduardo Ferreira Frias e Gerar Georges Delaunay. São Paulo: Centauro, 2002.

. Economia e sociedade: fundamentos da sociologia compreensiva, v. 2. Trad. Regis Barbosa e Karen Elsabe Barbosa, com rev. Gabriel Cohn. São Paulo: Editora UNB e Imprensa Oficial do Estado de São Paulo, 2004.

. Metodologia das ciências sociais, parte 1. Trad. Augistin Wernet. 4. ed. São Paulo: Cortez Editora; Editora da Unicamp, 2001, p. 109-114.

WEIGEND, Thomas. "Viktimologische und kriminalpolitische Überlegungen zur Stellung des Verletzten im Strafverfahren". Zeitschrift für die gesamte Strafrechtswissenschaft, v. 96, n. 3, p 761-793, 1984.

WEIS, Kurt; BORGES, Sandra S. "Victimology and rape: the case of the legitimate victim". Issues in Criminology, v. 8, n. 2, p. 71-115, 1973.

WEIßMANN, Martin; GRIEBAU, Teresa. "Gesellschaftstheorie nach Hegel. Symposium zu Axel Honneths 'Das Recht der Freiheit'”. Soziopolis, 2016. Disponível em: < https://pub.uni-bielefeld.de>. Acesso em 19 jun. 2018.

WELZEL, Hans. La dogmática del derecho penal. Trad. Carlos A. Finzi. In: WELZEL, Hans. Estudios de filosofia del derecho y derecho penal. Montevideo, Buenos Aires: B de F, 2013.

WERLE, Denilson Luis; MELO, Rúrion Soares. Reconhecimento e justiça na teoria crítica da sociedade em Axel Honneth. In: NOBRE, Marcos (org.). Curso livre de teoria crítica. Campinas: Papirus, 2008.

WESTPHAL, Kenneth R. "Hegel's standards of political legitimacy". Jahrbuch für Recht und Ethik/ Review of Law and Ethics, v. 10, p. 307-320, 2002.

WILLIAMS, Robert R. Hegel's ethics of recognition. Berkeley: University of California Press, 1997.

. Recognition: Fichte and Hegel on the other. Albany: State University of New York Press, 1992.

WILLIAMS, Timothy. "Trump wants to get tough on crime. Victims don't agree". The New York Times, Nova York, 11. aug. 2017. Disponível em: $<$ https://www.nytimes.com/2017/08/11/us/crime-victims-poll-trump-agenda.html $>$. Acesso em: 14 dez. 2017.

WOLHUTER, Lorraine; OLLEY, Neil; DENHAM, David. Victimology: victimisation and victim's rights. Nova York: Roudledge Cavendish, 2009.

WOOD, Allen W. Hegel's critique of morality. In: HEGEL, G.W.F. Grundlinien der Philosophie des Rechts. Org. Ludwig Siep. Berlim: Akdaemie Verlag, 1997, p. 147166. 
WÜRTENBERGER, Thomas. La situazione spirituale della scienza penalistica in Germania. Trad. Mario Losano e Franco Giuffrida Répaci. Milão: Giuffrè, 1965.

ZABEL, Benno. "Buchnotiz: Rechtsphilosophie als praktische Philosophie. Hegels Grundlinien der Philosophie des Rechts und die Grundlegung der praktischen Philosophie by Elisabeth Weisser-Lohmann“. Philosophische Rundschau, Mohr Siebeck, v. 58, n. 2, p. 178-182, 2011.

. Das Recht der Institutionen. Zu einer Kultur der Freiheit jenseits von Individualismus und Kollektivismus. In: SEELMANN, Kurt; ZABEL, Benno. Autonomie und Normativität: zu Hegels Rechtsphilosophie. Tübingen: Mohr Siebeck, 2014, p. 153176.

. “Del hecho al conflicto? Sobre el cambio de función del derecho penal de culpabilidad”. InDret, Barcelona, n. 01, jan. 2018.

. Die Ordnung des Strafrechts. Zum Funktionswandel von Normen, Zurechnung und Verfahren. Tübingen: Mohr Siebeck, 2017.

. "Die ordnungspolitische Funktion des Strafrechts“. Zeitschrift für die gesamte Strafrechtswissenschaft, v. 120, n. 1, p. 68-106, 2008.

. Die Vernunft des Leviathan. Zur Bedeutung der hegelschen Rechtsphilosophie als pragmatische Wissens- und Institutionenanalyse. In: VON HIRSCH, Andreas; NEUMANN, Ulfrid; SEELMANN, Kurt (org.) Strafe - Warum? Gegenwärtige Strafbegründungen im Lichte von Hegels Straftheorie. Baden-Baden: Nomos, 2011, p. 121-158.

"The institutional turn in Hegel's philosophy of right: towards a conception of freedom beyond individualism and collectivism”. Hegel Bulletin, v. 36, n. 1, p. 80104, 2015.

. What is a just order? On the current relevance of Hegel's concept of "Sittlichkeit". In: FERREIRO, Héctor; HOFFMAN, Thomas Sören; BAVARESCO, Agemir (org.) Os aportes do itinerário intelectual de Kant a Hegel. Porto Alegre: EDIPUCRS, 2014, p. 1520-1550.

ZEHR, Howard. Trocando as lentes: um novo foco sobre o crime e a justiça restaurativa. Trad. Tônia van Acker. São Paulo: Palas Athena, 2008.

ZURN, Christopher E. Introduction. In: AM BUSCH, Hans-Cristoph Schmidt; ZURN, Christopher $\mathrm{F}$ (ed.). The philosophy of recognition: historical and contemporary perspectives. Lanhan: Lexington Books, 2010. 